\title{
Pensar la violencia. Los lectores de Benjamín.
}

\author{
Thinking violence. Benjamin's Readers.
}

DOI: $10.32870 /$ sincronia.axxv.n80.2b21

\author{
Jesús López Salas \\ Departamento de Filosofía. Universidad de Guadalajara. (MÉXICO)
}

CE: jlsalasqt@gmail.com

\section{Esta obra está bajo una Licencia Creative Commons Atribución-NoComercial 4.0 Internacional}

Recibido: $18 / 01 / 2021$

Revisado: 30/04/2021

Aprobado: 16/06/2021

\section{RESUMEN}

En lo que sigue el lector encontrará una exposición del texto de Benjamín Para una crítica de la violencia, la interpretación que hace Derrida, Honneth, Žižek, entre otros; así como el comentario de Bernstein sobre esas lecturas. Derrida ha asociado el texto Benjamín a la "solución final", agrupándolo en las formas de pensamiento que justifican o hacen posibles actos similares a esos hechos. Honneth busca una salida afable, girando hacia una propuesta de revolución cultural. Žižek asocia el resentimiento que los humanos experimentamos para explicar sucesos históricos, que son ejemplo de violencia pura o divina, que tienen por causa el amor que procura el bien. Bernstein aceptará la lectura de Derrida, que considera producto de la imaginación. Aprecia la interpretación de Honneth, le parece iluminadora. Rechaza la idea de reducir la culpa a la conciencia de quien es responsable de actos violentos, que en silencio y de manera autónoma se juzgue a sí mismo por los actos cometidos, le parece inadmisible; considera que la violencia debe ser una discusión en comunidad apoyada por el pluralismo falibilista.

Palabras clave: Decisión. Manifestación. Revelación. Violencia. Mesianismo. Revolución. Derecho. Historia. Falibilismo. 


\begin{abstract}
In what follows the reader will find an exposition of Benjamin's text For a Critique of Violence, the interpretation made by Derrida, Honneth, Žižek, among others, as well as Bernstein's comment on those readings. Derrida has associated the Benjamin text with the "final solution", grouping it into the forms of thought that justify or make possible acts similar to those facts. Honneth looks for an affable outlet, turning towards a proposal for a cultural revolution. Žižek associates the resentment that humans experience to explain historical events, which are examples of pure or divine violence, which are caused by love that seeks good. Bernstein will accept the reading of Derrida, which he considers a product of imagination. He appreciates Honneth's performance, he finds it enlightening. He rejects the idea of reducing guilt to the conscience of the person responsible for violent acts, who silently and autonomously judges himself for the acts committed, seems to him inadmissible; he considers that violence should be a community discussion supported by fallibilist pluralism.
\end{abstract}

Keywords: Decision. Manifestation. Revelation. Violence. Messianism. Revolution. Right. History. Fallibilism.

Benjamín dejó un conjunto de tesis sobre la historia sin publicar 19 años después de la redacción del ensayo Para una crítica de la violencia; particularmente la IX tesis hace alusión a la violencia de una manera que conjuga el devenir histórico y la toma de conciencia del hacer humano, que hace evidente su responsabilidad sobre lo sucedido; muestra la presencia de Dios a través de un ángel que es testigo de lo acaecido, de un Dios ausente que regresa y encuentra los escombros de la muerte y la destrucción:

Mi ala está pronta al vuelo,

vuelvo voluntariamente atrás,

pues si me quedase tiempo para vivir,

tendría poca fortuna.

Gerhard Scholem, Saludo del Angelus 
Hay un cuadro de Klee que se titula Angelus Novus. Se ve en él un ángel al parecer en el momento de alejarse de algo sobre lo cual clava la mirada. Tiene los ojos desencajados, la boca abierta y las alas tendidas. El ángel de la historia debe tener ese aspecto. Su cara está vuelta hacia al pasado. En lo que para nosotros aparece como una cadena de acontecimientos, él ve una catástrofe única, que acumula sin cesar ruina sobre ruina y se las arroja a sus pies. El ángel quisiera detenerse, despertar a los muertos y recomponer lo despedazado. Pero una tormenta desciende del Paraíso y se arremolina en sus alas y es tan fuerte que el ángel no puede plegarlas. Esta tempestad lo arrastra irresistiblemente hacia el futuro, al cual vuelve la espalda, mientras el cúmulo de ruinas sube ante él hacia el cielo. Tal tempestad es lo que llamamos progreso (Benjamín, 2007, pp. 69-70).

Independientemente del contenido religioso de la tesis y que puede parecer absurdo aludir a Dios en la toma de conciencia de la destrucción y la catástrofe acontecida en el devenir de la humanidad, que en buena medida es responsabilidad del hombre, Benjamín nos obliga a pensar lo que no debería haber sucedido. Siguiendo la IX tesis podemos afirmar que el ángel es testigo, es conciencia de lo acontecido en la historia, su mirada le despierta del letargo y lo hace ver el desastre, la catástrofe y, a su vez, su impotencia, su incapacidad que lo arroja al futuro. Sólo hay muerte y destrucción, quizás Benjamín pensó en la tempestad que impulsa al ángel hacia adelante es el progreso en su marcha que lo aleja del Paraíso y arrastra al ser divino con fuerza superior a su voluntad. Esta tesis sobre la historia enfatiza que la vida humana sólo ha tenido lugar en la violencia y que el resultado del acontecer histórico es muerte y destrucción, no felicidad. La alusión al progreso como la causa que impide frenar la catástrofe y destrucción, lleva la conciencia impotente hacia un futuro cuya marcha no puede frenar. Conciencia y progreso aparecen como fuerzas en tensión. Esta débil oposición al progreso queda reducida a ser testigo y quizás a conservar en la memoria a las víctimas, a señalar los sucesos, fuera de eso nada.

Bernstein escribió un texto titulado Violencia. Pensar sin barandillas en 2013, ahí entabla un diálogo principalmente con cinco pensadores: Carl Schmitt, Walter Benjamín, Hannah Arendt, Frantz Fanón y Jan Assmann; su intención es filosofar en grupo, aclarar los pensamientos propios en 
el contraste con los ajenos, construir preguntas que sólo pueden venir de mirar lo diferente en lo familiar. No podía haber seleccionado un grupo tan distante en posturas e ideas, pero encuentra un hilo que le permite tejer su propia filosofía en el contraste y lo común que hay en ellas. La idea de decisión está presente a lo largo de su reflexión y diálogo, ya que constituye el punto nodal de la violencia, antes de hacer algo, hay que decidir hacerlo. Bernstein se siente estimulado porque las preguntas que va construyendo le ayudan a que su pensamiento aflore sobre un asunto tan complejo como es la violencia:

Existe una inquietante paradoja respecto a la violencia, hay demasiadas ideas y pensamientos sobre ella, sin embargo, en lugar que ello aclare la confusión, esta se hace más aguda: Lo paradójico es que a pesar de (o quizás debido a) que haya tanta discusión sobre la violencia, existe una enorme confusión respecto a que entendemos por violencia (Bernstein, 2015, p. 31).

De los cinco pensadores con los que dialoga Bernstein, el más enigmático quizás sea Walter Benjamín, su escrito Para una crítica a la violencia de 1921 ha suscitado múltiples interpretaciones en diversos sentidos y, como a otros, al filósofo norteamericano le genera una cierta inquietud singular.

Santiago Rey Salamanca, quien escribe la presentación de Violencia. Pensar sin barandilla, comenta lo siguiente sobre la forma que hace filosofía Bernstein en este texto: Establece un diálogo idealizado que trata de armonizar las posiciones de los interlocutores. Lo acompaña en sus conversaciones un espíritu agnóstico que le permite no otorgar valor a las propuestas que no emerjan del diálogo. No importa la distancia o la tradición de la que provengan los textos, su preocupación es reflexionar sobre nuestro tiempo, su intención es siempre hacer dialogar en su pensamiento las más diversas tradiciones.

Bernstein procura no ser víctima de lo que llama ansiedad cartesiana, que se caracteriza por la angustiante búsqueda de certeza indubitable o de un fundamento que sea un punto estable para creer y, con ello, cese la agonía. Hay que considerar lo contrario y suponer que en el cierre o 
conclusión no tendremos esa certeza y que el asunto o problema seguirá abierto. Su propuesta es pensar sin barandilla, como lo sugiere Arendt, es decir buscar constantemente un sentido, pero sin tener apoyo que condicione la búsqueda o la determine previamente. No partir de categorías predeterminadas, sean epistémicas, políticas, morales o culturales. Su tarea es abrirse paso entre posiciones preconcebidas.

El método de Bernstein se podría llamar dialógico, un diálogo radical que supone como necesario el pensar junto con otros, esto lo pone siempre en actitud hermenéutica al tratar de comprender e interpretar al otro, considerando y dotando de valor la probabilidad que la razón la tiene nuestro interlocutor.

Para Bernstein pensar es dar sentido al mundo en que vivimos, dotar a nuestra vida de posibilidades y, por ello, esta búsqueda nos conduce siempre a ir más allá, no creer que hay un punto último de llegada, sino que es un lugar de paso al que arribamos para continuar la marcha; nuestro pensar no se puede reducir a cálculo lógico, razón instrumental o conocimiento científico, a pesar de que puedan ser aliados en nuestro camino. Es una actividad que se debe realizar una y otra vez para que no se desvanezca, es nuestra obligación mantener vivo el pensar realizándolo cotidianamente y debemos cuidarlo para que no caiga en formas y modos que lo aniquilen o lo ponga en pausa.

Si bien "pensar sin barandillas" lo asume de Arendt, al igual que otras formas de pensamientos que son extrañas a nuestro pensador, como la búsqueda de fundamentos o la actitud nihilista, la deconstrucción o la teoría crítica, debemos siempre, no importa lo lejano o cerca que estemos, tener la actitud del pluralismo falibilista, que consiste en escuchar al otro y discutir todas las posibles alternativas. En asuntos complejos como permitir la violencia, la actitud debe estar basada en una decisión informada que implica un análisis riguroso y ser conscientes, con claridad, de las consecuencias que se siguen de ello. El análisis riguroso debe considerar nuestro problema desde los más diversos puntos de vista y la claridad se adquiere en el diálogo cuando confrontamos todos los puntos de vista, eso nos permite ver las singularidades y peculiaridades que estamos tratando. 


\section{La visión de la violencia de Benjamín}

Al ser Bernstein sumamente cuidadoso cuando lee a Benjamín expresa lo complejo que es seguirlo en su tránsito argumental, sobre todo cuando introduce la violencia como manifestación y las ideas de destino y revelación, cuya dependencia de su concepción de la violencia divina es determinante para dar sentido a lo dicho por el amigo de Brecht (Bernstein, 2015, p. 103).

Walter Benjamín nos presenta dos puntos positivos, que considero relevantes desde la perspectiva de Bernstein: uno, pensar la violencia como un fenómeno en sí, es decir, sin ligarlo como medio o como fin de otro fenómeno; esto permite preguntar éticamente de manera más clara: ¿moralmente es justificable la violencia? Lo complejo que enfrenta este planteamiento es que el sentido común inmediatamente la desplazar a un segundo plano, la violencia aparece como medio, es decir, se pregunta por qué aconteció, se busca la causa o razón apelando a la finalidad buscada; en oposición a ello Benjamín nos proporciona una vía para preguntar por ella independientemente del lugar que ocupe en la justificación, le interesa como hecho o acontecimiento sin más; habrá que distinguir los hechos, que es lo que acontece y forma el mundo; otro momento es cuando hablamos de ello, emitimos opiniones; al amigo de Brecht, en su crítica, le interesa que se le tome la violencia como hecho fundante. Un segundo punto importante, aun cuando Benjamín lo expone de manera secundaria, por no decir marginal, son las alternativas para actos humanos ajenos a la violencia, pequeña ventana que debemos resaltar. Bernstein comenta en este punto las interpretaciones de Butler y Critchley de las que difiere, ya que no consideran este claro del pensamiento de Benjamín, más bien otorgan sentido a la violencia divina como forma no violenta. Aun cuando nuestro filósofo reconoce afinidad en la actitud de ambos comentaristas con poder tener mecanismos que eviten la violencia, no está de acuerdo con su compresión del asunto.

David Hume supone que la relación entre causa y efecto, que a los ojos de los metafísicos aparece como ley natural universal, es sólo el hábito que nuestra mente construye a raíz de su aparición repetitiva de esa relación. Benjamín nos hace pensar de manera similar al respecto de la violencia y la justicia, por habito asociamos la violencia legítimamente aceptada a la acción que 
persigue fines justos, él quiere que pensemos la violencia con independencia de los fines; es decir, disociar esta relación y quitar el estatus de medio a la violencia. La intención de Benjamín es no dejar fuera de la crítica aquel tipo violencia que naturalmente consideramos que es justa.

Con el afán de precisar lo dicho, no podemos pensar la violencia sin una causa o fin perseguido, se podría replicar: no siempre se han elegido correctamente los fines; está desvinculación obedece a que los fines no corresponden con la violencia como medio, que son espurios, y habría que buscar los que dan razón de ella. Se puede elegir múltiples medios para alcanzar el mismo fin, ante esta alternativa siempre habrá una alternativa no violenta. La relación medios y fines, para entender lo que Benjamín trata de decir, independientemente que sean los únicos medios para garantizar la justicia, después de analizar todas las vías posibles y el resultado sean aquellos que son adecuados y reducen al mínimo el gasto e inevitablemente incluyen la violencia, hay que tomar la violencia de manera independiente, como aquello que acontece. Benjamín plantea observar la violencia sin vínculos, que rompamos con esta relación de medios y fines o cualquier otra justificación. En un primer plano la violencia aparece, se manifiesta y, en segundo momento, la justificamos, o en sentido contrario, nos damos una razón y actuamos, como consecuencia acontece la violencia; en uno y otro caso es el hecho lo que importa, lo que sucede y esto es la violencia.

Para Benjamín habrá que pensar la violencia en sí, no como idea platónica, sino como aquello que acontece sin necesidad de otro, esto surge de que regularmente se piensa como medio, sobre todo en el contexto del derecho, donde queda subordinada a los fines para su compresión; esta subordinación la reduce a ser una condición útil. De las dos concepciones del derecho sólo la positiva parece ayudar a comprender la violencia de manera independiente, dado que la relación de medios y fines se establecen por el devenir histórico y la convención humana. En este sentido Benjamín dice: "Es más, en principio, la violencia sólo puede encontrarse en el dominio de los medios y no en el de los fines" (Benjamín, 2001, p. 23). ¿Esta moralmente justificada la violencia? A esta pregunta se responde siempre apelando a los fines que se persiguen, Benjamín quiere que la formulemos sin relación a ningún fin: “Para llegar a una decisión al respecto, es necesario un criterio 
más fino, una distinción dentro de la esfera de los medios, independientemente de los fines que persigue" (Benjamín, 2001, p. 23).

Regularmente la concepción natural del derecho, al subordinar a fines justos el uso de la violencia, la legitima moralmente, ocultando el problema; resulta natural el uso de la violencia dado que es condición para alcanzar lo que justamente le pertenece al individuo, se dé de facto o de jure. Incluso el darwinismo es usado para justificarla, dado que hay fines naturales que se tienen que alcanzar para que la vida continúe su curso. En el otro sentido, el derecho positivo subraya su condición histórica, es decir no hay fines naturales, sino aquellos que por tradición y convención los humanos establecen, ello permite dirigir la crítica a los medios y no sólo respecto a los fines como el derecho natural. Esta posibilidad de dirigir la crítica a la violencia considerando los medios con independencia de los fines le parece muy favorable a los propósitos de Benjamín. A pesar de ello comparten ambas posturas un dogma fundamental:

[...] fines justos pueden ser alcanzados por medios legítimos y medios legítimos pueden ser empleados para fines justos. Es decir: El derecho natural aspira a "justificar" los medios por la justicia de sus fines; por su parte, el derecho positivo intenta "garantizar" la justicia de los fines a través de la legitimación de los medios (Benjamín, 2001, p. 24).

Para Benjamín debemos abandonar esta perspectiva para poder mostrar que el dogma fundamental de ambas visiones es falso, es decir, debemos partir que son irreconciliables los medios legítimos con los fines justos, y, con ello, poder buscar criterios independientes para cada uno. Para nuestro pensador esto es un hecho y, por ello, centra su atención sólo en la legitimidad de algunos medios que abarcan el ámbito de la violencia: "Por lo tanto, esta crítica permite localizar su punto de mira fuera de la filosofía del derecho positivo, pero también fuera del derecho natural" (Benjamín, 2001, p. 25). Aun cuando, lo singular de la visión del derecho positivo tenga sentido para la crítica de nuestro filósofo.

El primer problema es que no es fácil distinguir entre violencia legítima e ilegítima si asumimos al derecho positivo, dado que todo criterio tiene exclusivamente carácter histórico y, por 
ello, la clasificación es convencional. Podría no haber ningún criterio de reconocimiento o haberlo parcialmente, es decir tener la capacidad para sancionar un hecho violento y no otro. En este sentido Benjamín distingue fines sin reconocimiento, que llama naturales, frente a los que sí cuentan con un criterio, que llama fines de derecho (Benjamín, 2001, p. 26).

En el caso del individuo, sujeto a derecho, que pueda usar la violencia para satisfacer sus fines naturales ajenos a la ley, la tendencia del Estado es frustrarlos y establecer en su lugar fines de derecho que se realizaran en el marco de la ley y se pueda emplear violencia legal. Es natural que el orden jurídico histórico y determinado no abarque todo, los fines naturales de los individuos deben establecerse dentro de estos límites, pero siempre desbordan sus fronteras, de ahí que resulte siempre importante tratar de ajustar la norma a lo natural y lo natural a la norma. La educación será la estrategia para ajustar lo natural a la norma:

Todo fin natural de las personas individuales colisionará necesariamente con fines de derecho, si su satisfacción requiere la utilización, en mayor o menor medida, de la violencia... [y agrega,] [...] el derecho considera que la violencia en manos de personas individuales constituye un peligro para el orden legal (Benjamín, 2001, p. 26).

Por ello, el Estado juzga sólo la violencia que atenta contra los fines del derecho, pero difícilmente se pude sostener un sistema que sistemáticamente persiga y castigue fines naturales. Al enajenar el uso de la violencia de las personas individuales de manera legal el Estado tiene la intención de defender al derecho mismo. La violencia fuera de las instancias del derecho lo ponen en peligro. Benjamín se pregunta: ¿Cuál es la función que hace de la violencia algo tan amenazador para el derecho, algo tan digno de temor? (Benjamín, 2001, p. 27). Sin embargo, dice Benjamín, hay espacios donde se permite, de cierta manera se tolera, la persecución de fines naturales.

Los trabajadores con derecho a huelga, al igual que el Estado, son los únicos sujetos que legalmente pueden ejercer violencia. Ello es la causa que el Estado regularmente tienda a retirar el derecho a huelga de los trabajadores. El simple acto de abstenerse de trabajar y parar las 
actividades productivas se ha interpretado como violencia; específicamente para Benjamín este tipo de acción no es violenta:

Abstenerse de participar en una actividad o en un servicio, lo que equivale a una "ruptura de relaciones", puede ser un medio limpio y desprovisto de toda violencia. Y agrega, ...desde el punto de vista del Estado o del derecho, el derecho a huelga de los trabajadores no incluye de ninguna manera el derecho a la violencia, sino a sustraerse de ella si es utilizada por la patronal, huelgas ocasionales pueden ocurrir como declaración de "aversión" o “distanciamiento" respecto a la patronal (Benjamín, 2001, p. 27).

Los huelguistas deben abstenerse de toda violencia aun cuando puedan ser objeto de violencia por el Estado o por el patrón, pero el simple acto de abstenerse de trabajar es considerado como violencia, sin embargo, legítimamente aceptada en el marco jurídico. La huelga como violencia frente a la violencia del Estado es aceptada por que persigue ciertos fines legítimos.

En el sentido radical de una huelga general revolucionaria, donde el total de trabajadores entran en paro, el Estado la considera contrario a derecho:

Esta diferencia de interpretación ilustra la contradicción práctica del estado de derecho, y que consiste en que el Estado reconoce una violencia, cuyos fines naturales le son indiferentes, excepción hecha de caso grave de la huelga general revolucionaria a la que se opone vehementemente (Benjamín, 2001, p. 28).

Es este caso, un acto resulta violento aun cuando esté considerado legal por el derecho, dice Benjamín, es una contradicción práctica no lógica.

Benjamín introduce un término muy peculiar "violencia pirata" para subrayar el caso donde se busquen fines discrecionales que no pretendan modificar o fundar circunstancias nuevas; es quizás, este tipo de violencia pirata la que legitima al Estado, al permitir pluralidad de fines y sus potenciales colisiones, pero que distan de modificar el orden jurídico. Pero el potencial de transformación de la huelga lleva al Estado a considerarla como un tipo de violencia que atenta contra el derecho establecido. 
La violencia bélica muestra que la violencia contenida en la huelga no es aislada y que ambas provienen de la misma contradicción práctica. Es pirata esta violencia porque todo Estado entra en guerra para conservar el orden y la paz, sin embargo, una vez concluidas las hostilidades las nuevas circunstancias son reconocidas como nuevo "derecho". Ello permite a Benjamín extraer la siguiente conclusión: "Si se admite la violencia bélica como origen y modelo de toda violencia que persigue fines naturales, entonces todas estas formas de violencia fundan derecho". (Benjamín, 2001, p. 29). Por ello, toda persona individual tiene prohibido ejercer violencia. Y dice nuestro pensador: “[...] la violencia no se practica ni tolera ingenuamente". (p. 29).

El servicio militar obligatorio obedece a los fines del Estado, es el uso de la violencia ajena a la persecución de fines naturales y representa la total sumisión del ciudadano a las leyes. Con ello Benjamín expone que la primera forma de violencia funda derecho, mientras que esta es conservadora de derecho. En este punto Benjamín ha dado el giro que había prometido al inicio, ahora la violencia es la base del derecho y no al revés.

Las críticas al ejercicio del poder por imponer tareas y obligaciones a los ciudadanos por el Estado siguen sujetas a la visión tradicional de la violencia y del derecho, y con ellas se oculta que funda y conserva el derecho. Los pacifistas y activistas, incluyendo a los radicales, dejan fuera de su crítica la base ético-histórica del asunto. El imperativo categórico kantiano no es ajeno a la concepción positiva del derecho, se usa como crítica al Estado en defensa del individuo, trata de conservar el derecho de toda la humanidad en la personal de cada individuo, por ello es conservador de derecho. Es decir, según Benjamín, la crítica hecha, en el momento que redacto su reflexión, seguía atrapada en los derroteros de aquello que intenta criticar.

Lo alcanzado al momento nos permite afirma que todo individuo está atrapado en esta tensión de sus fines naturales frente a los fines de derecho. El Estado impone a través de sus instituciones un destino que limita los impulsos naturales del individuo, al contenerlos violenta su existencia, sujetándola a los parámetros establecidos en el derecho. Los fines naturales, es decir las necesidades que el sujeto trata de satisfacer, tienen su origen en la historia, necesidades que el individuo debe satisfacer en el marco de las condiciones sociales, por ello, en este contexto se 
permite derechos y se da a sí mismo obligaciones, que no coinciden siempre con lo establecido en los fines del derecho determinados por Estado que paulatinamente se petrifican.

Los fines del derecho que se imponen al individuo limitando o conteniendo sus fines naturales, se muestran como la garantía de cuidar de él de la amenaza de caer en manos de un criminal. Hay una prefiguración de la vida del individuo, es decir el Estado le da un determinado destino a su existencia y se compromete a su cuidado.

En el sentido anterior, en el marco de las críticas, quienes se oponen a la pena de muerte y elevan su oposición por considerar que trasciende el ámbito del derecho y que es una forma corrupta o de decadencia de la cultura; Benjamín considera que esta perspectiva, sin claridad, dirige su mirada al cuerpo completo de la ley y no a leyes aisladas; con ello se acerca sin alcanzar el origen del derecho:

Pero su sentido no era penalizar la infracción a la ley, sino de establecer el nuevo derecho. Y es que la utilización de violencia sobre la vida y la muerte refuerza, más que cualquier otra de sus prácticas al derecho mismo (Benjamín, 2001, p. 31).

Los ejemplos dados, la pena de muerte, la huelga y la inseguridad o fragilidad de la seguridad del individuo abren la posibilidad de crítica a la violencia en su cara de fundadora de derecho, así como de conservadora de derecho.

Algo muy peculiar en la exposición de Benjamín es su visión sobre la policía, le parece más "monstruosa" que la pena de muerte:

Lo ignominioso de esta autoridad consiste en que para ella se levanta la distinción entre derecho fundador y derecho conservador. La razón por la cual tan pocos sean conscientes de ello, radica en que las competencias de la policía rara vez le son suficientes para llevar a cabo sus más groseras operaciones, ciegamente dirigidas en contra de los sectores más vulnerables y juiciosos, y contra quienes el Estado no tiene necesidad alguna de proteger con las leyes. Del derecho fundador se pide la acreditación de la victoria y del derecho conservador que se someta a la limitación de no fijar nuevos fines. A la violencia policial se exime de ambas condiciones (Benjamín, 2001, p. 32) 
A pesar de que la policía está más allá de las funciones del derecho, según Benjamín, cumple una tarea de cuidar la esfera del destino que el corpus legal impone:

El "derecho" de la policía indica sobre todo el punto en que el Estado, por impotencia o por los contextos inmanentes de cada orden legal, se siente incapaz de garantizar por medio de este orden, los propios fines empíricos que persigue a todo precio. [Y agrega enfáticamente Benjamín:] En contraste con el derecho que reconoce que la "decisión" tomada en un lugar y un tiempo, se refiere a una categoría metafísica que justifica el recurso crítico, la institución policial, por su parte, no se funda en nada sustancial. Su violencia carece de forma, así como de irrupción inconcebible, generalizada monstruosa en la vida del Estado civilizado (Benjamín, 2001, p. 32).

El uso de la policía es más natural y congruente en el Estado de la monarquía absoluta: "Pero en las democracias su existencia no goza de esa relación privilegiada, e ilustra, por tanto, la máxima degeneración de la violencia". (p. 32).

En este sentido, la violencia como medio es justificada porque funda derecho o conserva el derecho. Moralmente es importante considerar si hay formas de regular los conflictos de interés de la humanidad por medios no violentos. Los contratos jurídicos no lo son, ahí se especifica cuándo un individuo puede hacer uso de la violencia o cómo será sujeto de violencia: "Toda institución de derecho se corrompe si desaparece de su consciencia la presencia latente de la violencia" (Benjamín, 2001, p. 33). Los parlamentos que parecen dar un tratamiento pacífico a los asuntos políticos no pueden dejar la coerción como elemento central de su tarea. Frente a estas dos falsas alternativas contra la violencia Benjamín subraya que en los acuerdos privados hay medios limpios de conformidad no violenta, basados en la "cultura del corazón": "Sus precondiciones subjetivas son cortesía sincera, afinidad, amor a la paz, confianza y todo aquello que en este contexto se deja nombrar" (Benjamín, 2001, p. 34). En el marco del Estado todo ello está determinado por el derecho y, como consecuencia, por la violencia. En sentido opuesto se manifiesta en estas 
relaciones privadas el movimiento de los individuos entre las cosas, por ello, los acuerdos civiles son ejemplo de ello, así como la conversación que no penaliza la mentira:

De ello se desprende que existe, precisamente en la esfera de acuerdo humano pacifico, una legislación inaccesible a la violencia: la esfera del "mutuo entendimiento" o sea, el lenguaje. La violencia de derecho finalmente se infiltró en ella, mucho más tarde y en pleno proceso de degeneración, al imponer castigo al engaño.... El engaño o la estafa, exentas de violencia, estaban libres de castigo según el postulado "ius civile vigilantibus scriptum est", o bien "ojo por dinero" tanto en el derecho romano como en el germano antiguo (Benjamín, 2001, pp. 34-35).

Este acuerdo entre particulares, sujetos a la fuerza de la palabra, basado en verse cara a cara y sellar el compromiso, según Benjamín, permite "contratos" no jurídicos ajenos a la violencia. Luego se dio la intromisión del derecho en los acuerdos entre particulares, no por asuntos morales, sino para evitar la violencia que estableciera nuevo derecho, con ello el Estado eliminó la posibilidad del empleo de medios limpios y no violentos. Esto podía ser usado en asuntos privados y políticos, incluso la huelga podría disponer de medios limpios por esta vía.

Siguiendo a Sorel ${ }^{1}$ introduce una diferencia: huelga general política y huelga general proletaria. La primera es para reformar los mecanismos del Estado y, con ello, fortalecer el poder de la violencia. El origen de la segunda fue introducido por los proletarios alemanes para terminar con la violencia estatal y estaba basada, según Benjamín, en medios limpios, con ello, se trataba de introducir un tipo de trabajo diferente al establecido y no impuesto por la fuerza: "Esta concepción profunda, ética y genuinamente revolucionaria impide que se adscriba a semejante huelga general un carácter violento, so pretexto de sus posibles consecuencias catastróficas" (Benjamín, 2001, p.36).

El sector productivo supuso que su fin era dañar los intereses de los propietarios, por eso señala Benjamín: “Aun así, no debe juzgarse la violencia de una acción según sus fines o

\footnotetext{
${ }^{1}$ Sorel, Georges; (1978): Reflexiones sobre la violencia; Buenos Aires; Ediciones la pléyade; Trad.: Luis Alberto Ruiz.
} 
consecuencias sino sólo según la ley de los medios" (Benjamín, 2001, p. 37). Que en este caso no fueron violentos. A diferencia de ello Benjamín comenta que no fue el caso de la huelga de médicos, cuyas consecuencias fueron desastrosas para los enfermos y pacientes.

Benjamín reconoce que hay cierta posibilidad de medios limpios y no violentos:

Se trata de una tarea delicada que se resuelve de manera más resolutiva recurriendo al arbitraje, pero que significa un método fundamentalmente más elevado que el del arbitraje, por trascender los órdenes del derecho, y, por consiguiente, también la violenta. La diplomacia, como asimismo el trato entre personas privadas, desarrolló formas y virtudes que, no por haberse convertido en exteriores, siempre así lo fueron (Benjamín, 2001, p. 38).

Benjamín permite ver que el nombre que nombra realmente las cosas y fenómenos, que subyace en el lenguaje humano, permite alcanzar acuerdos que conservan el poder de la palabra, ello frente al contrato basado en el lenguaje ajeno al nombre, cuya esencia artificial impide el entendimiento entre los hombres.

Con ello, Benjamín abre la posibilidad para no emplear la violencia. Y considera que el derecho se muestra como el monopolizador de toda forma de violencia y se pregunta: si hay otras formas de violencia diferentes a las propias del derecho. Hace un símil, donde la verdad es a los lenguajes vivos lo que la violencia al derecho; esto para mostrar lo difícil que es concebir otra forma de violencia, afirma lo siguiente: "Si bien la razón es incapaz de decidir sobre la legitimidad de medios y la justicia de fines, siendo más bien una violencia fatal la que los determina, por encima de ella, lo hace Dios". (Benjamín, 2001, p. 38).

Esta violencia fatal, propia de Dios, está por encima de la violencia que da origen al derecho. La condición histórica de los fines y medios proporciona cierto relativismo a la visión del derecho, de tal forma que los mismos fines, en contextos distintos, no legitiman lo mismos medios, de ahí que la razón no pueda dar cuenta de ellos, sino sólo apelando a su historicidad. La existencia de la violencia tiene su raíz en el hecho que Dios expulsó del paraíso al hombre; ese es el origen, no como fundamento sino como hecho. La violencia aconteció de mano del hombre como hecho. El hombre 
extraviado juzga y es juzgado porque no posee el conocimiento, lo perdió con su expulsión, su lenguaje carece del poder nominativo que Dios le concedió, de ahí que sus sentencias no nombren nada y sólo queda la violencia como recursos para establecer orden, que por más racional y justo que sea, no deja de ser un artificio y una convención histórica (Benjamín, 2010b, pp. 144-162).

La experiencia cotidiana nos muestra que hay otro tipo de violencia ajena al derecho: la ira, que irrumpe en violencia sin ser medio para ningún fin, es decir, sólo se manifiesta. Al igual que los dioses del mundo mítico que castigan súbitamente, no hay regla o norma previa, sólo amenaza y hecho. Con el ejemplo de la ira, Benjamín nos conduce a buscar otro camino de su crítica, a la vez más profundo, y lo encuentra en el mito.

La violencia mítica es pura manifestación de los dioses. Níobe es castigada por Apolo y Artemisa, matan a sus hijos y le imponen que en silencio pague su culpa, el haber desafiado el destino dado por los dioses. Esta violencia funda derecho, no castigan con base en criterios previos, sino que al castigar instauran orden y derecho, establece frontera y garantiza el poder. Benjamín refuerza esta idea con el principio: ignorar la ley no exime de castigo. Esta afirmación permite reforzar el derecho escrito frente a las prescripciones míticas, ayuda a entender el castigo y la violencia como manifestación.

Para Benjamín la violencia mítica es antecesora de la violencia como medio, que es fundamento del Estado y del derecho. La violencia mítica y la violencia como medio obedecen a la misma naturaleza. Frente a ella está la violencia pura e inmediata que es de Dios. Subraya Benjamín que violencia pura es opuesta a la violencia mítica:

En tanto que la violencia mítica es fundadora de derecho, la divina es destructora de derecho. Si la primera establece fronteras, la segunda arrasa con ellas; si la mítica es culpabilizadora y expiatoria, la divina es redentora; cuando aquella amenaza, ésta golpea, si aquella es sangrienta, ésta otra es letal, aunque incruenta (Benjamín, 2001, p. 41).

Para ejemplificar la violencia pura o divina, expone el hecho de la rebelión contra Moisés a las faldas del monte Sinaí, donde Dios castiga a los rebeldes sepultándolos vivos, no hubo amenaza, sólo 
golpe y aniquilación; fue un acto incruento y redentor; no hay sangre. Frente al caso de Níobe, a quien se le mantiene viva para que sufra su culpa, a los infractores que atentaron contra Moisés se les redimide en acto a través de la muerte. Dussel subraya que "Ese Dios, y esa violencia divina, es semítica y crítica, no es griega ni moderna [...]" (Lizarazo, 2012, p. 47). En ello interpreta correctamente a Benjamín, es el dios judío, único con la capacidad de ejercer violencia pura; le parece que es crítica por que está en oposición a la violencia instrumental y dado que no proviene de la cultura hegemónica; pero en sentido estricto, la violencia no es crítica en ningún sentido ni en ninguna de sus formas, solamente es, acontece, es un hecho. Respecto a este punto Petar Bojanić subraya la forma en que se interpreta erróneamente la idea de revolución de Benjamín, así como su uso de la figura de Korah, quien es el villano que se opone al sacerdote Arón y al profeta Moisés. Korah se revela ante lo establecido por Moisés, ante la ley que éste introduce, se podría considerar el primer revolucionario sin embargo es castigado. El vínculo entre revolución y mesianismo tiene su primer acto, para seguir a Bojanić en su idea del teatro de lo mesiánico: “[...] la violencia última y divina que Dios ejercerá sobre él será para Benjamín una violencia puramente revolucionaria cometida precisamente contra este primer revolucionario" (Bojanić, 2010, p. 139). La idea es simple, todo aquel que se revela frente al poder oficial, por ese hecho es revolucionario; de ahí que Korak es revolucionario. Sin embargo, en sentido opuesto la intervención revolucionaria es de Dios, porque funda una nueva época histórica; Korah quiere conservar el mundo mítico y por ello se rebela, su rebelión atenta contra la introducción del monoteísmo por parte de Moisés, que sería el verdadero acto revolucionario. Sólo es revolucionario para Benjamín aquello que haga posible el reino de Dios, pero no cualquier dios, tiene que ser judío o semita, no griego o de cualquier otra tradición.

El profesor Aureliano Ortega Esquivel se ayuda de la idea de violencia mítica para esclarecer los niveles de violencia en México. Atribuye a Benjamín el mostrar que el derecho y la justicia son antitéticos, que la tarea de aquel es impedir que se realice esta; ya que la justicia es de las sociedades sin Estado. La tarea de Ortega Esquivel es mostrar, a través de Benjamín, que el Estado de excepción es la cotidianidad en la vida humana: 
Se insiste en ello porque es preciso comprender que la violencia no es una perversión, una desviación: la violencia es estructural, es constitutiva del "Estado de derecho" y no una violación del "Estado de derecho"; es por ello que se la percibe como "negación determinada" de la justicia y a esta como la gran ausente en toda formación orgánicoconcreta de Estado (Corona, 2018, p. 236).

Ello ayuda a comprender que una sociedad sin violencia será aquella sin clases, la que supere con la abolición de las diferencias sociales que son defendidas por el Estado. Si bien en esta interpretación hay congruencia con el pensamiento de Benjamín, existe también un punto de ruptura, la sociedad sin violencia es la del reino de Dios, no es suficiente que no haya clases.

Al no existir derecho, Dios educa a través de la revelación y los milagros; por ello, atenta contra bienes, derecho, vida y lo que esté asociado con ellos, pero jamás de manera absoluta contra las almas de los seres vivientes, de ahí que pueda redimir las almas (Cfr: Benjamín, 2001, p. 42). El mesianismo de Benjamín es regresar a esa vida sin derecho, sin Estado, sin violencia mítica, donde Dios juzgue y castigue.

Esta violencia pura, Benjamín supone, tendrá múltiples oposiciones, sobre todo porque aparentemente justifica la violencia de unos contra otros, esto el mandamiento "no matarás" lo impide, no es un criterio regulador y, por ello, sancionador de la conducta, es más bien una pauta de comportamiento, un mandamiento que constituye la vida misma. En caso de que alguien trate de fundamentar el mandato diciendo que la vida es sagrada, sea de vegetal, animal o humano y, con ello, tener derecho a castigar a otro por haber matado a un ser vivo o el asesinar en legítima defensa, por error lo reducirá el mandamiento a criterio de derecho, no lo conservará en su estatus sagrado. Pero el mandato es inamovible, es la presencia de Dios que impide quitar la vida a otro; pero una vez que se ha consumado el asesinato no podemos saber el juicio divino sobre ello:

Este no representa un criterio para alcanzar un veredicto, sino una pauta de comportamiento para la persona o comunidad activa que debe confrontarlo en la intimidad, y que en casos tremendos tiene que asumir la responsabilidad de sustraerse a su mandato (Benjamín, 2001, p. 42). 
No es posible que un humano condene a otro con base en este mandato, pero sí puede orientar su vida a través de él. Benjamín afirma que las normas de Moisés no constituyen derecho, son mandatos análogos a los morales que deben guiar nuestra conducta y cuyo cumplimiento apela a la libertad de cada uno y, con ello, a la costumbre de la comunidad a la que se pertenece.

El revolucionario que asesine al tirano podría ser juzgado con el mandamiento como simple instrumento jurídico, cual si la vida biológica del tirano fuera más valiosa que su vida como hombre justo; quienes lo juzguen de esa forma creerán tener buenas razones para suponer que, al privar de la vida al tirano, el insurgente atenta contra la voluntad de Dios. La existencia justa, es decir la vida justa, es más valiosa que la mera existencia o vida. El tirano al igual de Korah está luchando por mantener el mundo sumergido en el mito y el derecho. Pensar la vida como sagrada corresponde al mito y al derecho, no a Dios:

Probablemente no valga la pena investigar el origen del dogma de la sacralidad de la vida. Posiblemente sea algo muy reciente; una última confusión de la debilitada tradición occidental, por querer recuperar al santo que ha perdido en la inescrutabilidad cosmológica (Benjamín, 2001, p. 43).

En sentido estricto el ser humano se debe abstener de quitar la vida a otro, pero si eso sucede tampoco puede ser juzgado con la ley mosaica, eso será asunto de Dios, cuya justicia acontecerá en el juicio final. La violencia que Dios castiga es la que emerge del acto de juzgar, es decir, de usar la ley dada por la divinidad como instrumento jurídico.

Contrario a ello, Dussel supone que Benjamín si abre la posibilidad en este texto para considerar la vida como sagrada (Lizarazo, 2012, p. 48). Error similar al de Karmy Bolton en su texto: Violencia mítica y vida desnuda en el pensamiento de W. Benjamín, donde supone que Benjamín aporta fundamentos para la biopolítica (Karmy, 2005). Sólo para resaltar que para nuestro filosofo la vida desnuda no es sagrada, sagrada es la vida humana justa a los ojos de Dios. 
No es suficiente el pensar desde el ahora, hay que ir al devenir histórico para saber cómo la violencia funda derecho o conserva el derecho, en su naturaleza dialéctica. Tampoco es suficiente el mostrar esta oscilación, sino hay que ver cómo determina una era histórica y abre la posibilidad de otra, este es el punto determinante para saber si el acto es revolucionario o no.

Pero si la violencia llega a tener, más allá de derecho, un lugar asegurado como forma limpia e inmediata se deduce, independientemente de la forma y posibilidad de la violencia revolucionaria, a qué nombre debe atribuirse la más elevada manifestación de la violencia a cargo del hombre. Para el ser humano no es ya posible sino urgente decidir cuándo se trata efectivamente de violencia limpia en cada caso particular. [...], la fuerza redentora no está al alcance de los humanos (Benjamín, 2001, p. 44).

Los actos revolucionarios pueden ser coadyuvantes de la violencia limpia, es decir, pueden hacer la voluntad de Dios en el mundo, como instrumento de la manifestación de la justicia divina. Quizás debemos decir que para ser revolucionarios deben propiciar sólo violencia limpia. Pero no será el establecer otro Estado u orden jurídico, más bien es similar a San Agustín, traer a la tierra el reino de Dios, restaurar el paraíso perdido, volver al primer momento donde Adán no había pecado. Quienes realicen acciones en este sentido serán redimidos:

Podría manifestarse en la verdadera guerra de la misma manera en que se manifestará a la masa de criminales en el juicio divino... La violencia divina, insignia y sello, jamás medio de ejecución sagrada, podrá llamarse, la reinante (Benjamín, 2001, p. 45).

Dussel dice erróneamente al respecto:

La coacción legítima de liberación, revolucionaria, no es violencia, aunque en ciertos casos (como el de G. Washington, M Hidalgo y Costilla o la "resistencia francesa" ante la invasión nazi) pueda ser armada, y que tampoco todavía es legal (porque no se ha instaurado un orden nuevo jurídico) (Lizarazo, 2012, p. 51). 
Supone que los actos revolucionarios no son violentos, porque las acciones llevadas a cabo son justas, y según él, esto se debe a que son acciones de los desposeídos frente a los poderosos; con ello distorsiona la idea de Benjamín. En sentido más radical afirma que las comunidades indígenas están fuera de toda violencia, incluso en los castigos que impone a quienes han cometido algún delito contra otro miembro de la propia comunidad:

La institución policial, así como el nuevo Estado, tienen como fundamento la legitimidad de la comunidad revolucionaria, cuya praxis no es violenta (según la descripción dada). Por ejemplo, las comunidades indígenas castigan al asesino de otro miembro de la comunidad con alimentar, trabajando su campo, a la familia del asesinado, de por vida. Es un castigo justo que la policía comunal hace cumplir. No se trata de violencia sino de justicia (Lizarazo, 2012, p. 52).

Es decir, todo acto de control del Estado (no revolucionario) reprime a los desposeídos y eso es violencia, pero todo acto revolucionario, al ser justo, no es violento. No hay nada más alejado de lo afirmado por Benjamín.

Siguiendo a Benjamín, los revolucionarios serán el brazo ejecutor de Dios. ¿Cómo saber que un acto contribuye a reestablecer el paraíso? La respuesta sólo la tiene Dios.

Tomar conciencia del devenir histórico, que para Benjamín está asociado con el derrotero del hombre, después de su caída en el pecado original, y que, justo por ello, está determinado a ser victimario y víctima de la violencia, cualquier forma de organización social o política implica la coerción y la violencia como realidad inmanente, no hay forma de escapar de ella. Por ello afirma al final de texto: La crítica de la violencia es la filosofía de su propia historia.

La violencia no es inherente a la naturaleza humana, es condición de la pérdida del nombre, esa capacidad humana de llamar las cosas por lo que son, que ha olvidado, y cuyo olvido teje la trama de la historia (Benjamín, 2007, pp. 144-162)². Hay cercanía con la idea de los griegos al considerar que sólo el hombre que no sabe comete injusticia, con lo que afirma Benjamín, la

\footnotetext{
${ }^{2}$ Véase también las páginas: 139-153, en: (Benjamín, 1986).
} 
pérdida del uso del nombre (Muñiz-Hubermann, 1993); ambas tienen como base la ignorancia, si bien lo helenos, al igual que la ilustración, suponen que el hombre se puede educar y, con ello, aprender a pensar por cuenta propia y alcanzar la mayoría de edad para dejar la violencia en un pasado prisionero de la irracionalidad; nuestro filosofo sujeta esta superación a un acto ajeno a lo humano, si bien pude ser instrumento, sólo podrá ser eso, instrumento, dejando a la voluntad de Dios la liberación ${ }^{3}$. El ser humano sufrirá violencia porque esa es su condición como pecador, sea mítica, jurídica o divina; pero al ser ajena a su naturaleza está latente la posibilidad que el propio hombre con sus limitados recursos pueda construir mecanismos que lo libren de esta carga.

\section{Las interpretaciones del ensayo}

Bernstein entablará un diálogo con interpretaciones que le ayudarán a mostrar sus pensamientos sobre el tema tratado por Benjamín; así Marcuse, Derrida, Zizek, Honneth, Butler y Critchley a través de sus propuestas permitirán a nuestro pensador precisar ideas y reflexiones respecto a Para una crítica de la violencia. Desde el inicio alude al precepto "no matarás", que es considerado por Benjamín como una pauta de conducta y no una norma jurídica para juzgar, condenar o castigar; habría que tomarlo como criterio para erradicar la violencia parcialmente y sólo tolerarla en casos excepcionales, según Bernstein. Se distingue de la interpretación de Butler y Critchley porque debe tomarse la decisión de permitir la violencia después de una concienzuda discusión colectiva y no hacerla en soledad y de manera individual, siendo consciente de las consecuencias que esta permisibilidad implica. Por otro lado, le causa inquietud la interpretación de Derrida que considera que los pensamientos de Benjamín, en ese texto, justifiquen o abran la posibilidad a hechos similares a la solución final y las cámaras de gases. Valora de este modo el ensayo de Benjamín:

Más aún, su texto no provee una base adecuada para comprender la violencia y su interacción con la no-violencia. El poder del ensayo -la razón por la cual ha suscitado tantos comentarios e interpretaciones creativas- radica en las preguntas que plantea y no en las respuestas que ofrece (Bernstein, 2015, p. 35).

\footnotetext{
${ }_{3}^{3}$ Para ver la diferencia de la concepción del nombre véase: (Muñiz-Huberman, 1993).
} 
Marcuse ha dado una interpretación del ensayo, calificada por Honneth como minimizadora, donde la violencia divina se debe entender como la lucha de los oprimidos contra los opresores y su mesianismo como un tropo que expresa una verdad histórica, considera que no tiene nada que ver con su visión religiosidad, debe mantenerse en el campo de la sociología no religioso; ello a casusa que los oprimidos viven cotidianamente en Estado de excepción y la revolución se convierte en una necesidad histórica. El mesías es la voluntad y conducta de todos aquellos que sufren bajo la opresión. La conclusión es que Benjamín es un pensador revolucionario. Para Bernstein la lectura de Marcuse no ayuda a comprender la relación entre violencia mítica y violencia divina, hay una minimización hacia categorías exclusivamente sociales e históricas, en ello coincide con Honneth (Bernstein, 2015, pp. 104-105).

En ese sentido, Bernstein pone énfasis en la interpretación de Butler sobre la violencia divina que formula Benjamín, y que considera como no-violenta. Esta aparente contradicción Butler la salva haciendo una lectura del mandamiento "no mataras" en un sentido ético y no jurídico, diciendo que es una pauta de conducta que Dios, bondadoso y amoroso, dio a los hombres para evitar la violencia. Frente a la violencia mítica y jurídica que Butler llama violencia coercitiva, opone la violencia no coercitiva que sería la violencia divina; de ahí que el precepto caiga dentro de la libre decisión del individuo y sea el contraste con la decisión forzada que impone el derecho. En este sentido hay posibilidad para la no violencia, pero queda abierta la opción para actos violentos en situaciones extremas y que deberán dirimirse en soledad, en la conciencia de cada uno. Critchley se apoya en Butler para confirmar una ética de la resistencia y considera que el precepto no debe interpretarse como imperativo categórico por la razón que no podemos conocer las circunstancia en que se deba aplicar, es decir no tiene validez universal. Quien sea violento y llegue a privar de la vida a otro ser vivo deberá enfrentar en soledad y con su conciencia la responsabilidad de sus actos. Bernstein se siente distante de esta interpretación, no porque él no desee la no violencia, sino porque Benjamín no afirma lo que dice Butler y Critchley; no afirma que la violencia divina sea noviolenta, ni que el precepto sea moral. La violencia pura o no coercitiva es la violencia 
revolucionaria de los actos mesiánicos que es aceptada como tal por ambos intérpretes y en eso Marcuse está más cerca del pensamiento de Benjamín considera Berntein. El ejemplo es la rebelión y muerte de Korah o Core, como lo cita Bernstein, es prueba de la violencia pura o mesiánica, o como la llama Butler no coercitiva. Dice Bernstein: "No hay ninguna razón para pensar que esta violencia 'incruenta' es no-violenta" (2015, p. 112). Para Bernstein la decisión de optar por la violencia debe ser discutida en pluralidad, desde los puntos de vista más rigurosos hasta alcanzar la mayor claridad posible y el castigo o la culpa debe ser el juicio razonado colectivamente, no de manera individual ni en soledad.

\section{Desenmascarar la simulación de la justicia}

En el caso de Salinas Paz pone en un grupo de pensadores a Benjamín, entre otros está Marx, Bourdieu, Habermas, Foucault, Agamben, Levinas, Gramsci, Althusser, para afirmar que a través de ciertas categorías que estos proponen se puede desenmascarar las simulaciones de legitimidad de la violencia; estas simulaciones, que carecen de autoridad moral, las realiza el derecho y la filosofía no genealógica. A Benjamín particularmente le atribuye el introducir la idea de violencia permitida en un orden de poder y legitimación para controlar a los desposeídos. Esta práctica discursiva otorga condición de legitimación al uso de la injusticia disfrazada, encubierta de legitimidad. Con ello, permite Benjamín tener una mirada fuera del derecho positivo y natural, deja ver los cuerpos sometidos y asimilados, dominados y reprimidos, violentados por los aparatos de poder:

No es lo mismo el uso de la violencia para defender nuestros fines de grupo, que el uso de la violencia para defender los fines impuestos de manera simulada por el estado hegemónico. El punto clave es el establecimiento de un aparato estatal hegemónico que, de dirigir los intereses de la nación, pasa a dominar, reprimir, asimilar y violentar para imponer los fines de grupo como fines nacionales (Salinas, 2018, p. 14).

Hay según lo dicho dos usos de violencia, uno para conservar el poder y la otra defender nuestros fines de grupo. Estos últimos obedecen a reconocer diferencia de género, cultura, etnicidad y clase: 
Desde esta perspectiva crítica de Benjamín, el Estado se convierte en el gran criminal fundador de derecho que sirve para impones fines de grupo, simulando dirigir, pero dominando, reprimiendo, criminalizando y ejerciendo la violencia; Estado hegemónico que en-cubre los fines de clase bajo el disfraz de interés y fin, necesidad y proceso de la nación, mecanismo de imposición (Salinas, 2018, p. 14).

La crítica para Salinas Paz son aquellos procesos para des-armar la palabra ilegitima disfrazada de legitima. Nuestro comentarista críticamente nos muestra que nos hacen creer que, a su juicio, antes de la existencia del orden jurídico no hay delito alguno, porque no hay un código que lo tipifique, de tal forma que éste tiene lugar después que la ley ha sido elaborada y aceptada; donde son calificando ciertos hechos como actos criminales, pero esto no es así; por ello, Benjamín nos mostró que la violencia funda derecho y conserva derecho, poniendo la validez del orden del derecho en un Estado, a decir de Salinas Paz, la represión no se des-arma al interior del debate jurídico, porque es previa a la conformación de la ley, es decir, lo que está considerado como no legal es previo al establecimiento de la ley, los opresores han determinado que la protesta y rebelión de los desposeídos es un delito mucho antes que exista el aparato jurídico para juzgarla y, en sentido opuesto, el hecho que la ley sancione esto como delito, es porque existe antes que se dé la represión. Este juego le da esa intimidación a la criminalización de los reprimidos, son culpables antes de cualquier orden jurídico y el reclamo de sus derechos está tipificado con anticipación:

La violencia fundadora planteada por Benjamín es el proceso en que, para diseñar, promulgar y operar una ley se recurre a compromisos ajenos al sentido de comunidad (unidad sobre la diferencia, siendo que ésta es la permanente realidad propia de toda comunidad), y suprime la diferencia en favor de la unidad imponiendo fines, visiones e intereses de un grupo sobre el otro, triunfo de la mismidad, razón instrumental. (Salinas, 2018, p. 16).

Hay un uso de la legitimidad cuando se establece los derechos de unos pocos como los derechos de todos. Para hacer más agudo el problema introduce un ejemplo Salinas Paz, pone la idea de nuda 
vida de Agamben para hablar de lo no asimilado por los aparatos del Estado, es decir, a través de la dialéctica, que funda y conserva el derecho, permite la violencia sobre el otro, sobre lo no asimilado, a lo que Benjamín denomina "la vida como algo sagrado". La crítica permite defender la vida, la existencia, frente a la injusticia disfrazada de justicia eliminando la enajenación (Salinas, 2018, p. 17). Esta idea de la vida como sagrada es ir más allá de simple vida, es permitir la vida humana; idea que no está en lo afirmado por Benjamín. Esta dialéctica que muestra que la violencia que conserva derecho debilita la que funda derecho, respectivamente es el uso de los aparatos de represión del Estado que, en nombre de la justicia, acallan las voces de todos, que podrían establecer lo nuevo.

Usando a Marx, a través de los términos de Gramsci y Benjamín, se puede comprender adecuadamente su tarea de desenmascarar esa idea del hombre abstracto de Bruno Bauer, propia del derecho como instrumento de legitimar la justicia que oculta la injusticia.

A pesar de que se atribuye correctamente a Benjamín el tratar de salir de la visión del derecho, Salinas Paz lo introduce por la puerta de atrás, al suponer que se trata de establecer un derecho u orden social de los desposeídos, sin comprender que Benjamín trata de superar esta etapa y, como dice Honneth, observar ese mundo desde otro lugar, ajeno al derecho y al orden social. Quizás los pensamientos que tratan de decir cuál es el origen de la violencia no ayuden a evitar que suceda ni cómo juzgarla con menos errores. Salinas Paz supone que la violencia que conserva el derecho es del Estado opresor, mientras que la que funda derecho es la visión de los oprimidos, estratégicamente de aquella que minimiza a esta; pero una vez que estos, los oprimidos, asuman el poder tendrán que asumir el papel de conserva el derecho; olvidamos que la idea de Benjamín es superar este esquema y lograr en un futuro un mundo ajeno a la ley, el derecho y el Estado. Aun cuando no se afirma explícitamente el uso de la violencia por los desposeídos está implícita en lo afirmado. En oposición a ello se deben buscar alternativas no violentas, como propone Bernstein, que pondría el pluralismo falibilista como criterio para saber tomar decisiones en situaciones donde hay que recurrir inevitablemente a la violencia, que implica la discusión en pluralidad y otorgando alto valor a la opinión de los otros, tanto previo a las acciones violentas 
como después que estas se hayan realizado, es decir, ese lugar hay que construirlo a través del continuo pensar donde esté incluido el otro.

\section{Resentimiento, amor y violencia}

A Bernstein le parece equivocada la interpretación del ensayo de Benjamín dada por Žižek, sobre todo en la referente a precepto "no matarás" y a su interpretación de la violencia divina. En su valoración de la opinión de su interlocutor dice lo siguiente: “Debido a la juguetona exuberancia de su astucia dialéctica, siempre es un reto precisar lo que Žižek está tratando de decir" (Bernstein, 2015, p. 113). Parte de la polémica entre Critchley y Žižek, que recíprocamente se distinguen clarificando sus perspectivas, el primero no logra rescatar la violencia divina como no violencia y su propuesta anarquista refuerza la violencia del Estado; en reciprocidad, el segundo es calificado como defensor del autoritarismo leninista.

Žižek nos presenta, usando las técnicas cinematográficas, que es común en sus análisis, la confrontación de la visión de Dios sobre el mundo humano frente la perspectiva subjetiva del criminal o la víctima; el lugar de la cámara que capta el hecho desde planos altos y ajenos a los actores, desde donde Dios observa los sucesos, crímenes de los que es testigo. Ello ayuda a Žižek a introducir el tema central de su interpretación sobre el ensayo de Benjamín y, por ello, relaciona su IX tesis sobre la historia. La participación de Dios en los sucesos sea pasiva, activa o indiferente, permite dar sentido a los hechos como justos, papel similar que otorga Žižek a la Aufklärung (ilustración). A los ojos del hombre puede ser un castigo que Dios impone a los humanos por su decadencia, por la corrupción en la que han caído, o puede ser el otorgar oportunidades que permita mostrar lo mejor que hay en ellos ante la catástrofe (Žižek, 2009, pp. 211-215).

La búsqueda de sentido profundo obliga a buscar el papel que Dios juega en los sucesos humanos: sea que castigue al pecador o que brinde oportunidades para mostrar la virtud, en oposición a ello, hay quienes tratan de dar explicaciones sin acudir a la intervención del Dios trascedente: 
Nuestra primera conclusión debe ser que la compresión de Benjamín de la "violencia divina" no tenía nada que ver con la violencia terrorista ejercida por los fundamentalistas religiosos de hoy, que pretenden actuar en nombre de Dios y como instrumento de la voluntad divina [...] (Žižek, 2009, p. 2019).

Para Žižek la violencia es más asunto de resentimiento humano, los actos violentos que ejecutan los religiosos en nombre de Dios, según su perspectiva, obedece a que pretenden adelantar el juicio final que consumará Dios en un momento posterior y limpiar el mundo del pecado. La ira se acumulada, conforme al análisis de Žižek, ha pasado de la tradición judeocristiana a la visión secular, donde debemos ubicar el comunismo y al fascismo. Con lo dicho podríamos preguntar ¿Qué relación hay entre la visión de Benjamín sobre la violencia y el resentimiento?

Cuando se hiere a un sujeto de modo tan devastador que la idea de venganza de acuerdo con el ius talionis es no menos ridícula que la promesa de reconciliación con el perpetrador una vez expiada su culpa, lo único que queda es persistir en la "denuncia incesante de la injusticia" (Žižek, 2009, p. 225).

¿Qué actitud se debe tomar ante el crimen? Hay un conjunto de términos involucrados: resentimiento, perdón, castigo y olvido. Podrían combinarse de diversas formas, una de ellas es "perdono, pero no olvido"; otorgado el perdón se ha generado en el victimario el sentimiento de culpa, dice Žižek: el super yo freudiano. Inmediatamente relaciona a Dios con el super yo, la víctima en un giro freudiano se convierte en culpable al tomar la actitud soberbia de elevarse sobre el victimario perdonándolo y evidenciando su culpa; por ello, Dios lo castiga, por la soberbia que le permite enjuiciar y castigar al culpable, su pecado es dar el perdón, elevándose con soberbia por encima del criminal, con ello se hace alusión a que sólo Dios puede enjuiciar y castigar:

Sólo Dios mismo (o, en términos estables, quien se halla en la cúspide del poder, el rey o el presidente), merced a su posición excepcional, tiene la prerrogativa de borrar la culpa de los demás. Nuestro deber es actuar de acuerdo con lo lógica de la justicia y castigar el 
crimen: no hacerlo acarrea la blasfemia de ponernos nosotros mismos al nivel de Dios, actuando con su autoridad (Žižek, 2009, pp. 229-230).

Dios perdona la culpa y sólo él puede perdonarla, de ahí que cualquier humano debe abstenerse de ello. ¿Cómo evitar caer en el pecado de la soberbia? No asumiendo el papel de Dios y para ello el humano debe enjuiciar y castigar y, una vez hecho esto, esperar el dictamen divino por estos actos, evitando la soberbia. Qué sucede ante actos como el holocausto, pensando que no tenemos otra alternativa que lo dicho:

[...] un crimen tan monstruoso (el asesinato de los judíos europeos a manos de los nazis) que las tres primeras posturas pierden su impacto. Uno no puede perdonar y mucho menos olvidar tal acto, pero tampoco pueden castigarlo adecuadamente (Žižek, 2009, p. 230).

Es una situación límite que excede, según Žižek, la capacidad humana de justicia. En oposición al imperativo categórico kantiano, Žižek comenta, no es sí la libertad en un nóumeno o fenómeno, sino: "[...] lo verdaderamente traumático es la libertad misma, el hecho de que la libertad ES posible, y buscamos desesperadamente determinaciones "patológicas" para poder evitar esta circunstancia". (Žižek, 2009 p. 232).

Nuestra propia libertad nos causa temor, nos pone en aporía, pero ello no exime que tratemos de explicar una de sus consecuencias: la violencia. Pensar la violencia pura como un sueño izquierdista de venganza cargado de resentimiento, que se muestra en los hechos históricos como la revolución francesa, la comuna de Paris de 1848 o la revolución rusa de 1917, ayudará a evitar buscar una explicación que recurran a lo trascendente, a Dios. Cuál es el papel de Dios ante hechos de este tipo de violencia, refiere Žižek a Benjamín, exponiendo una cita larga que reflexiona sobre el mandamiento "no matarás", este mandamiento antes que se cometa el crimen, el ser humano sabe que está siendo observado por Dios, quien está atento a los acontecimientos, se reduce a ser un simple testigo; después de la acción, para el humano, estrictamente no cabe emitir un juicio 
sobre lo sucedido, dado que el mandamiento no es un criterio jurídico, es tarea que le corresponde a Dios y sólo él puede emitir un juicio; luego cometa:

Este es el dominio de la pura violencia divina que es el dominio de la soberanía, el dominio en el que matar no es expresión de una patología (idiosincrasia, impulso destructivo), ni un crimen (o su castigo), ni un sacrificio sagrado. No es tampoco algo estético ni ético ni religioso (un sacrificio de los dioses oscuros). Así que, paradójicamente, la violencia divina se superpone en parte a la disposición biopolítica de los homini sacer: en ambos casos, matar no es un crimen ni un sacrifico. Los aniquilados por la violencia divina son plena y absolutamente culpables, y no se les sacrifica, puesto que no lo merecen ni tampoco que algún dios les acoja, sino que son aniquilados sin sacrificio alguno ¿De qué son culpables? De llevar una mera vida (natural) (Žižek, 2009, pp. 234-235).

Para Benjamín la finalidad de la violencia divina es poner fin a la violencia mítica y al derecho, esto es lo que olvida o deja de lado Žižek (Bernstein, 2015, p. 115), ello porque introduce desde el psicoanálisis la noción de resentimiento como eje central para su interpretación, en ello hace énfasis Bernstein, que considera que Žižek limitó su análisis al caso de la violencia mítica.

La ausencia de una perspectiva que permita visualizar la violencia divina y que sólo el creyente hace visible impide identificarla, no sabemos cuándo acontece, por ello Bernstein está en desacuerdo con lo que propone Žižek:

[...] uno debe combatirla en soledad, asumiendo su plena responsabilidad de ella. En otras palabras, la "violencia divina" no tiene nada que ver con los estallidos de "locura sagrada", con aquellas bacanales en las que los sujetos renuncian a su autonomía y su responsabilidad, puesto que es un poder divino superior el que actúa a través de ellos (Žižek, 2009, p. 237)

La violencia divina es la purificación, no de la culpa por el crimen cometido, sino del derecho y el mito: "La violencia divina es una expresión de pura pulsión, de no muerte, del exceso de vida, que golpea a la 'vida desnuda' regulada por la ley" (p. 237). La diferencia entre el holocausto y la 
revolución es que lo primero queda como medio, es decir atrapado en la estrategia medios-fines, mientras que la segunda no le debemos buscar un sentido profundo:

[...] la violencia divina no sirve a ningún medio, ni siquiera al castigo de los culpables para así restablecer el equilibrio de la justicia. Es tan sólo el signo de la injusticia del mundo, de ese mundo que éticamente "carece de vínculos". Esto, sin embargo, no implica que la justicia tenga un significado, sino que más bien es un signo sin significado y la tentación que debemos resistir es la que Job resistió con éxito, la tentación de proporcionar un "sentido profundo" (Žižek, 2009, pp. 236-237).

La intervención de Dios, a través de un acto violento, es un ejemplo de lo que será el juicio final, para Žižek es un signo de la impotencia de la divinidad, muy diferente al Estado de excepción y a la explosión anárquica. Žižek expone un punto interpretando la revolución francesa, cuyos protagonistas se propusieron ser tan terribles que el pueblo no deseara ser el protagonista de esas acciones, es decir, es un acto preventivo que realiza la justicia que el pueblo desea, bajo el dicho "la voz del pueblo es la voz de Dios". Ello a sabiendas que la culpa quedará en la responsabilidad y la conciencia soberana de cada revolucionario: "[...]no da al agente licencia para matar con una especie de inocencia angelical" (Žižek, 2009, p. 239). En este punto Žižek está más acerca de Schmitt que de Benjamín, conforme a lo que dice Bernstein, y los ejemplos que pone están relacionados con el problema de la ira, esa manifestación de la violencia que caracteriza su modalidad mítica (Bernstein, 2015, p. 115).

La violencia divina pertenece al reino del acontecer, no del juicio: "El riesgo de interpretarlo y asumirlo como divino es lo propio del sujeto: la violencia divina es el trabajo del amor del sujeto" (Žižek, 2009, p. 240). Para Žižek hay una paradoja, el revolucionario está en una pasión por el amor que tiene a la humanidad y lo que hace es castigar para corregir sus fallas: "[...] el amor sin crueldad es impotente; la crueldad sin amor está ciega, no es más que una pasión breve que pierde su duradero filo" (2009, p. 241). Esta crueldad eleva sus actos de corrección, violentos, por encima de lo meramente humano. La violencia divina es un acto de amor, es corregir lo que está mal, aquello 
que pone en peligro a la humanidad, y quienes son responsables y, por ello, enemigos del revolucionario deben ser amados; concluye Žižek que para Benjamín el dominio de la violencia pura es el domino del amor.

Este acto de amor-odio no nos libra de la arbitrariedad, si bien Žižek nos aporta algunos elementos emocionales en su análisis que acompañan las acciones de los sujetos, reduce la perspectiva de la violencia divina a lo que Benjamín llama violencia mítica, poniéndola en la tesitura de medios y fines; que si bien, comparte el hecho del manifestarse, del acontecer de la violencia, no por ello supera este punto que es fundamental para el amigo de Brecht y que subraya Bernstein con toda claridad. El otro punto, la decisión, que involucra al agente de la acción violenta, lo deja exclusivamente en el tribunal de su conciencia individual y la soledad, que para Bernstein debe llevarse a la discusión en pluralidad y análisis más riguroso.

\section{Deconstrucción de la violencia}

Qué ha detonado en interés por el ensayo de Benjamín, Bernstein afirma que la causa es la interpretación de Derrida:

Una de las razones principales por las que ha habido un constante, casi obsesivo, interés por la interpretación y la reinterpretación de Para una crítica de la violencia se debe, en gran medida, a la ya célebre, detallada, arriesgada y extremadamente polémica interpretación deconstructiva de Derrida en su texto Fuerza de Ley: El fundamento místico de la autoridad (Bernstein, 2015, p. 116).

Derrida interroga el ensayo de Benjamín en un evento que discuten el nazismo y la "solución final", con ello lo ubica en un contexto ajeno, por no decir, opuesto al lugar que tradicionalmente se le ha dado. Los calificativos de Derrida llaman poderosamente la atención de Bernstein sobre las ideas del ensayo: inquieto, enigmático, terriblemente equivoco y obsesionado por la destrucción radical, de la exterminación, de la aniquilación total y de la aniquilación del derecho y de la justicia, esto último, en cuanto es la manifestación de la tradición griega y la ilustración. En el caso de la justicia 
que se deriva de la violencia divina y que parece la única posible, Derrida la considera no deconstruible porque su naturaleza es el manifestarse y sólo puede ser visible a través de la revelación.

Derrida en su análisis del texto centra su atención en la firma de Benjamín que está plasmada al final del escrito. Lo relevante del caso es la importancia que tiene el nombre para los judíos, según Scholem todos reciben un segundo nombre que guardan en secreto fuera de los círculos íntimos del judaísmo, Benjamín recibió el nombre de Ángelus Santander (Scholem, 2003, p. 77-81). Dice Derrida “[...] y es del enigma de esta firma de lo que quería hablar" (Derrida, 2016, p. 70); de la firma y del contraste de la fuerza que pone nuestro filósofo en la violencia divina o pura que súbitamente aniquila y redimide. Derrida no deja de interpretarlo como una obsesión por el exterminio y la aniquilación total:

[...] obsesionado por el tema de la destrucción radical, de la exterminación, de la aniquilación total, y en primer término de la aniquilación del derecho, si no de la justicia; y entre estos derechos, los derechos del hombre, al menos tales como éstos pueden ser interpretados en una tradición iusnaturalista de tipo griego o del tipo de la Aufklärung. (Derrida, 2016, p. 70).

Esta renuncia a la justicia y razón humana tal como se desarrolló en la ilustración, la tradición griega y occidental, colapsa los mecanismos para enjuiciar a los asesinos responsables de los peores horrores. La deconstrucción interroga los textos para hacerlos colapsar en sí, hacerlos caer en aporía; para Derrida, el texto de Benjamín, al quitar o aniquilar los únicos medios para castigar a los culpables colapsa en su pretensión de hacer la crítica de la violencia. La base que está en el pensamiento de Benjamín es la tradición judía, la firma y el nombre ubican al berlinés como enviado de Dios que revela la catástrofe por venir, el apocalipsis y el juicio final. Esta arista no es tratada por Bernstein en su análisis de la interpretación de Derrida, sino que Derrida es cuestionado por su propia firma en el ensayo Fuerza de ley. 
Como se ha mostrado, Benjamín quiere probar que la violencia antecede al mito y al derecho que, al emerger, producto del pecado, sale a su paso la justicia divina, la violencia pura que Dios opone y que es radical, aniquilante y redentora. Siguiendo con Derrida, que considera que la "solución final" o esa "cosa sin nombre" que interpela a la ley de la representación y que demanda lo más borrable pero exigente, que es la ley de la memoria, cómo podría tener cabida en la propuesta de Benjamín.

Otro asunto que Derrida subraya es "[...] cómo se articula el pensamiento del nombre con la obsesión y la lógica del espectro" (Derrida, 2016, p. 71), asunto que nos conduce a la responsabilidad, culpabilidad, sacrificio, solución, castigo y expiación: "Zur Kritik der Gewalt no es sólo una crítica de la representación como perversión y caída del lenguaje sino de la representación como sistema político de la democracia formal y parlamentaria”. (Derrida, 2016, p. 71).

El texto de Benjamín dice Derrida, se ubica en la ola antiparlamentaria y anti-Aufklärung de la época, donde el nazismo sobresale por su radical oposición. Al identificar la visión basada en la representación como democracia formal y Aufklärung, donde está como antecedentes el pensamiento griego, renunciado con ello a la posibilidad del acuerdo racional sea en su versión racional o mítica, en términos de Benjamín.

Acontecido el pecado, la soberbia de Adán que procuró usar el lenguaje que Dios le otorgó para nombrar en sentido opuesto e intentó crear con él, introdujo con ello la violencia en el mundo, la violencia humana en su manifestación mítica o jurídica, a lo que Dios opuso la violencia de la redención. El lenguaje posadánico tiene en su germen la violencia, Derrida comentando Para una crítica de la violencia dice:

La lógica profunda de este ensayo lleva a cabo una interpretación del lenguaje -del origen y experiencia del lenguaje- según la cual el mal, es decir, la potencia letal, le viene al lenguaje por la vía, precisamente de la representación, es decir, por medio de la dimensión representativa, mediadora, y en consecuencia, técnica, utilitaria, semiótica, informativa, otras tantas potencias que arrastran al lenguaje y lo hacen caer e ir a parar lejos o fuera de su 
destino original que fue la apelación, la nominación, la donación o la llamada de la presencia en el nombre. (Derrida, 2016, p. 71).

El origen del mito y del derecho proviene de la violencia y esta de la confusión del nombre, que constituye el centro y fundamento del lenguaje. Ambos mito y derecho tienen su base en el acto de juzgar, de establecer lo bueno y lo malo, lo justo e injusto, lo verdadero y lo falso; esta necesidad tan humana requiere del juicio que está compuesto principalmente por el nombre y, se debe decir, principalmente porque los otros términos que se usan para conformar un juicio están subordinados a él. El nombre que nombra un objeto o fenómeno se estableció por acuerdo en un momento determinado de la historia y, a su vez, será cambiado en otro acuerdo en un momento posterior. Siguiendo esta lógica, la violencia podrá cambiar y ser diferente, pero se manifestará siempre; el origen de la violencia está presente para superarla debemos reestablecer la función dada por Dios al nombre y, con ello, cesará la necesidad de juzgar.

Lo polémico para muchos pensadores de la interpretación de Derrida consiste en las interrogantes que plantea:

¿Qué habría pensado Benjamín, o al menos que pensamiento de Benjamín está virtualmente formado o articulado en este ensayo -y cabe preguntarse si es anticipable- a propósito de la "solución final", de su proyecto, de su puesta en práctica, de la experiencia de sus víctimas, de los juicios, procesos, interpretaciones, representaciones narrativas, explicativas, literarias que han podido intentar medirse con la cosa?¿Cómo habría hablado Benjamín, cómo habría querido que se hablase, se representase o prohibiese representar la "solución final"? ¿Cómo la habría identificado, asignado su lugar, sus orígenes, sus responsabilidades (como filósofo, como juez o como jurista, como moralista, como hombre de fe, como poeta, como cineasta)? (Derrida, 2016, p. 71).

Estas preguntas nos conducen a poner el texto de Benjamín en una tesitura que la mayoría de sus comentaristas omiten. Al considerar que la violencia es inevitable y sobre todo al alto valor que asigna a la violencia que aniquila en un sólo acto, a la que extermina; aunado a ello está la idea de la 
intervención humana como instrumento divino en actos mesiánicos. Para resaltar el punto, es relevante poner la crítica que realiza Benjamín justo al lugar a donde nos conduce: hechos o actos divinos en el marco de la tradición.

Derrida reconoce que lo difícil de vincular el texto de Benjamín con la "solución final" radica en su filiación que regularmente sus diversas interpretaciones hacen con lo mesiánicorevolucionario, además su suicidio aconteció en 1940, antes de los hechos del holocausto, pero a pesar de ello hay elementos que permite esta asociación. Su propuesta de lectura y de interrogación del texto de Benjamín discurrirá en dos sentidos: Uno. Dirigir la mirada a la psyché judeo-alemana y compararla con pensadores alemanes, en este sentido es obligado contrastar a Benjamín con Carl Schmitt o Heidegger; así como su oposición a la Aufklärung y a la democracia parlamentaria, por su interpretación de la guerra, la violencia, el lenguaje y su idea de la destrucción. Derrida resalta que estos pensadores al igual que Benjamín tienen por base la tradición y la memoria "auténtica". Dos, la otra cara es cuestionar el sentido aporético al texto. Aporía que se desprende de su autodestrucción, producto de la violencia de su firma, recalca Derrida, de la firma divina:

Sino que al final de un texto que se las ingenia para desconstuir y descalificar todas las oposiciones que ha llevado a cabo de manera crítica (especialmente la de lo decidible y lo indecidible, del juicio teorético y de la acción revolucionaria, de la violencia fundadora y de la violencia conservadora dentro del derecho mitológico, opuesto el mismo a la justicia violenta divina, etc.), al final de un texto que no queda ningún otro contenido (teórico, filosófico o semántico), quizás ningún contenido "traducible" fuera de la singularidad de su propio acontecimiento, fuera de su propia ruina, una frase última, una frase escatológica nombra la firma y el sello, nombra el nombre, y lo que se llama "die waltende". (Derrida, 2016, pp. 7677).

El fallo o sentencia con el que se cierra el texto hace suponer que Benjamín tuvo una iluminación mística, la visita de un ángel que lo iluminó y le revelo la naturaleza de la violencia. La frase referida por Derrida es la siguiente: “La violencia divina, insignia y sello, jamás medio de ejecución sagrada, 
podrá llamarse, la reinante" (Benjamín, 2001, p. 45), y lo enigmático que subraya Derrida: cierra con la firma que es el nombre de nuestro filósofo. La violencia reinante, que es insignia y sello, está más allá de la compresión humana, toca la experiencia de la mística benjaminiana. El nombre secreto de Benjamín, que nos refiere Scholem: Ángelus Santander; el ángel trae la buena nueva, pero esto no sucede con Benjamín, en más de una ocasión trae el anuncio de la catástrofe (Scholem, 2003).

Para Derrida es un juego de palabras que aleatoriamente se combinan en el uso de Walter y walken, podríamos aventurar que anuncia el fallo que revela la voluntad de Dios a través del texto de Benjamín. Dice Derrida es un texto firmado y fechado; la fecha lo hace distante en apariencia de la "solución final". Esta distancia podría hacer pensar, da lugar a pensar, que la "solución final" no está en el origen o naturaleza del nazismo, sino que fue un hecho contingente y que bien pudo no suceder. Derrida nos muestra que hay hechos que acontecen porque hay pensamientos que los hacen posible, que si seguimos en ese derrotero es natural que sucedan lo que está prefigurado en las ideas; si bien es cierto que no hay una secuencia lógica que permita que de un pensamiento se siga una acción; sin embargo, hay cierta responsabilidad de quienes alientan o fomentan por sus pensamientos los hechos específicos.

Derrida, en lo que denominó Post Scriptum, ensaya algunas ideas que probablemente Benjamín haya pensado sobre la "solución final" partiendo que fue un fenómeno inherente en la lógica del nazismo, pero en situación extrema. Uno, la radicalización se debió a que el nazismo llevó al extremo el nombre, es decir, el lenguaje alcanzó el límite como instrumento. Dos, el Estado del nazismo sustituyó el Estado basado en la democracia parlamentaria y con ello fundó derecho que legitimo la "solución final". Tres, el uso corrupto de la policía por la democracia parlamentaria para controlar la vorágine social de la época llegó a su extremo máximo en el nazismo con la "solución final". Cuatro, el mito y la violencia mítica se expresan en el nazismo en su vertiente más acabada porque está mediada por la Aufklärung y la tradición helénica, dice Derrida: "Y el nazismo fue una revolución conservadora de ese derecho" (2016, p. 144).

Para Derrida la "solución final", siguiendo al entramado del texto de Benjamín, no tiene el rasgo de singularidad ya que liga pecado, decadencia del lenguaje, violencia, mito, derecho y policía 
como un tipo de destino, frente a su opuesto que ligaría violencia divina y mesianismo. Dos tipos de destino, pero ambos bajo el sello de la violencia:

[...] no se puede pensar la singularidad de un acontecimiento como la "solución final", como punta extrema de la violencia mítica y representacional, en el interior de su sistema. Hay que intentar pensarlo a partir de su otro, es decir, a partir de lo que ha intentado excluir y destruir, exterminar radicalmente, y que lo obsesionaba a la vez por dentro y por fuera (Derrida, 2016, p. 145).

Hay que pensarlo desde la singularidad de la firma y del nombre, afirma Derrida, porque se ha tratado de borrar, junto con las víctimas, su reclamo de justicia y su recuerdo en la memoria. En referencia a diferentes intérpretes que han minimizado lo acontecido en la "solución final" o de hechos parecidos, llegan al límite del mal por dos lados, justificando lo acontecido como hechos naturales de la guerra, dado que son hechos que suceden regularmente, así como reducirlos a hechos jurídicos que acontecieron en el contexto de decisiones de Estado legalmente justificadas y fueron consecuencias naturales de la contienda política, piensa Derrida:

Desde este punto de vista, Benjamín habría considerado quizás vano y sin pertinencia, en todo caso sin pertinencia a la medida del acontecimiento, todo enjuiciamiento jurídico del nazismo y de sus responsabilidades, todo aparato judicial, toda historiografía que siguiese siendo homogénea al espacio en el que el nazismo se ha desarrollado hará la solución final, toda interpretación basada en conceptos filosóficos, morales, sociológicos, psicológicos, o psicoanalíticos, y sobre todo en conceptos jurídicos (en particular los de la filosofía del derecho, ya sea de estilo aristotélico o del estilo de Aufklärung) (Derrida, 2016, p. 147).

Esta reflexión permite ver las consecuencias de seguir al pie de la letra lo afirmado por Benjamín, para quien el derecho y la justicia, al estar fundadas en el mito y el Estado y, a la par de lo sucedido, tienen un origen y fundamento común. Esta nulidad que Benjamín atribuye a estos medios para castigar a los culpables imposibilita hacer justicia, no se puede usar instrumentos en cuyo germen se nulifican en sí mismos. 
Un texto debe ser congruentes con sus propios preceptos y dado el rechazo a la violencia que da origen al mito y al derecho por parte de Benjamín, resulta inconsistente aplicar la justicia, quienes los usen agudizarían la violencia y la injusticia, este es el sentido aporético que subraya Derrida del texto de Benjamín.

Esta alternativa del destino, orilla al ser humano a tomar una decisión, optar por la violencia del derecho, el mito y la policía, por un lado; mientras la otra alternativa está cerrada para él, el mesianismo y la violencia divina:

Lo cual quiere decir también que la interpretación de la "solución final", así como de todo lo que constituye el conjunto y la delimitación de los dos órdenes (mitológico y divino), no se encuentran a la medida del hombre. Ninguna antropología, ningún humanismo, ningún discurso del hombre sobre el hombre, puede medirse con la ruptura entre lo mítico y lo divino, ni, en consecuencia, con esa experiencia límite que es un proyecto como la "solución final" que intenta pura y simplemente aniquilar lo otro de la violencia mítica, lo otro de la representación, la justicia divina y lo que puede dar testimonio de ésta, es decir, el hombre en tanto es el único ser que, no habiendo recibido su nombre de Dios, ha recibido de Dios el poder y la misión de nombrar, de dar él mismo un nombre a su semejante y de dar un nombre a las cosas. (Derrida, 2016, p. 148).

Esta interpretación de la "solución final" como la aniquilación del hombre, tal como Dios lo creo y le otorgó el lenguaje y la tarea de nombrar, y quien no tiene la posibilidad de enjuiciar, dado que nombrar y representar son acciones diferentes y el juicio corresponde a la representación y no al nombrar. El juzgar sería sólo una representación, una ficción producto de la carencia del nombre, del no saber qué es eso que acontece como un hecho. De ahí que desde el texto de Benjamín no es posible enjuiciar a los criminales o asesinos sin abandonar su base mítica y jurídica.

Para Derrida el texto tiene elementos que en sí son rechazables, entre lo que se encuentra su crítica a la Aufklämung, la teoría de la caída, la autenticidad originaria, su concepción del lenguaje, la crítica a la representación y a la democracia representativa; pero existe algo que le causa más incomodidad, dice lo encuentro temible, incluso insoportable, se trata: 
La de pensar el holocausto como una manifestación ininterpretable de la violencia divina en cuanto que esta violencia divina sería a la vez aniquiladora, expiadora y no-sangrienta... El juicio de Dios golpea a los privilegiados, levitas, los golpea sin preaviso, sin amenazas, fulmíneamente, y no se detiene frente a la destrucción. Pero el juicio de Dios es también, justamente en la destrucción, purificante, expiador, y no se puede dejar de percibir un nexo profundo entre el carácter no sangriento y el purificador de esa violencia. (Derrida, 2016, pp. 149-150)

Las cámaras de gas y los crematorios son formas no sangrientas de exterminio. Lo sostenido en el texto, dice Derrida:

[...] se asemeja demasiado, hasta la fascinación y el vértigo, a aquello mismo contra lo que hay que actual y pensar, contra lo que hay que hacer y hablar... Pero si hubiese una enseñanza que sacar, una enseñanza única entre las enseñanzas siempre únicas del asesinato, aunque sea singular, de todos los exterminios colectivos de la historia (pues cada asesinato individual y cada asesinato colectivo es singular, y así infinito e inconmensurable) la enseñanza que podemos sacar hoy - y, si podemos, debemos-, es que debemos pensar, conocer, representarnos, formalizar, juzgar la complicidad posible entre todos estos discursos y lo peor (aquí, la "solución final") (Derrida, 2016, p. 150).

Esta obligación de todo filósofo y hombre de letras es ajena a Benjamín y Heidegger. Su pensamiento hundido en la tradición y su actitud de creer que poseen la certeza de vivir la experiencia auténtica, originaria y fundante, colapsa y destruye cualquier posibilidad de superar la condición donde la violencia es soporte y fundamento de la vida humana.

Los pensamientos que conforman al nazismo y que lo constituyen en su esencia tienen muchas formas de manifestarse, una de ellas es la defensa y el alto valor que otorgan a la tradición, en cuyo marco tienen la certeza que Dios les ha otorgado una tarea y que les autoriza a tomar la vida de otros. Quizás debemos abandonar toda tradición, junto con sus dioses, sean del color que sean y sujetarnos a la precaria razón humana. 
Para Bernstein la interpretación de Derrida no discute temas relevantes, tales como el precepto "no matarás" y el ejemplo de Korah o Coré. Le parece polémica la atribución de la indecidibilidad que hace Derrida al poner en aporía el ensayo que cierra y hace imposible el uso del derecho y la justicia para juzgar a los culpables, por su filiación a la tradición de la ilustración y la cultura griega-occidental; por el otro lado la imposibilidad de la decidibilidad sin certeza de la justicia divina:

La conclusión de Derrida sobre las diversas maneras en que la indecidibilidad habita en el corazón mismo de ambas formas de violencia es "consistente" con su propia práctica deconstructiva, ya que su propósito es mostrar que la aparente clara y "antitética" distinción que Benjamín esboza entre estas dos formas de la violencia no es tan clara y distinta como Benjamín supone [...] Lo que si se quiere decir es que nunca escapamos a la indecidibilidad. (Bernstein, 2015, p. 120).

Bernstein replica que habría que cuestionar por la firma de Derrida en su texto Fuerza de Ley, es decir, deconstruir su firma, determinar del lugar desde donde habla. En este sentido la lectura de Derrida que vincula el ensayo de Benjamín a la solución final le parece inapropiado a Bernstein, por la fecha de su escritura, sin embargo, considera que es posible hacerlo, ya que es "evaluativa, prescriptiva y no constativa [...]" (Bernstein, 2015, p. 121), por ello, dice Bernstein:

Dada la concepción deconstructiva de la indecidibilidad esta lectura no es accidental sino necesaria. Derrida no está diciendo que la tentación de adoptar esta interpretación se sigue de la compresión de Benjamín de la violencia divina. Pero dada la indecidibilidad del texto de Benjamín, no podemos excluir tal interpretación - o al menos, la tentación de interpretar la violencia divina de esta manera- (Bernstein, 2015, p. 122).

holocausto permite reflexionar y poner en marcha preguntas y nuestro pensar, pero no deja de ser imaginación. Para Ricardo Forster la interpretación de Derrida es tortuosa, dice no debemos olvidar que Benjamín piensa la catástrofe en relación con la esperanza y se mueve entre ambos polos, la 
destrucción y su posible superación (Forster, 2014, p. 432). Benjamín era partidario de asaltar el poder como lo había propuesto y realizado Lenin, no de la democracia (p. 442); por ello resulta una falacia trasladar a un pensador de los años 20 a nuestra época (p. 443). A pesar de que Forster toma en cuenta la influencia de la tradición judía la reduce a mero adorno que acompaña al pensador en su producción intelectual; en ese sentido toda idea traída de la tradición es neutra, no tiene peso en los pensamientos y acciones de los hombres.

\section{Violencia divina como revolución cultural}

Axel Honneth, al igual que Bernstein, en su ensayo El rescate de lo sagrado desde la filosofía de la historia. Sobre la "crítica de la violencia" de Benjamín, procura dotar a su lector de los elementos que formaron las circunstancia en las que Benjamín escribió su ensayo, que considera dotado de “[...] una sutileza que confunde profundamente" (Honneth, 2009, p. 101). Considera que había en el momento de la redacción del trabajo una discusión sobre la legitimidad de la violencia donde convergían preocupaciones sobre el derecho, la historia y la religión; a lo que debemos considerar que Benjamín era altamente influenciable por las circunstancias cultuales. Desde muy temprano, afirma Honneth, Benjamín pensó que se debía superar la fuerte influencia del utilitarismo, que era el origen de todo tipo de mal, al reducir al esquema medios-fines las acciones determinantes de la vida humana, a lo que opuso una postura que pugnaba por un decisionismo religioso. Pensó que Dios y el lenguaje, como posteriormente lo será la crítica literaria y la literatura, eran acciones que no caían en el esquema medios-fines.

Sus lecturas de Bloch, Sorel, Unger, Peguy, Schoen y la amistad con Scholem (Cfr: Scholem, 2014), que a pesar de sus diferencias entre ellos compartían en común el rechazo al utilitarismo, lo impulsan a ir más allá y busca aclarar la idea de experiencia, que encuentra limitada en Kant, el filósofo cumbre de la ilustración y que Benjamín aprecia, pero considera muy pobre su concepción en este punto determinante. Benjamín se encontraba muy cerca de la acción política motivado por la pauperización que generaba el capitalismo, la vida inmovilizada y el caso de Palestina; pasaba de ver la política desde cierta aristocracia intelectual a simpatizar con el proletariado (Cfr: Honneth, 
2009, p. 106). Este hecho Honneth lo valora en buena medida porque anticipa lo que se ha llamado la concepción de la Escuela de Frankfort; pero en ese momento: "[...] descubre en lo político la estructura de una finalidad en sí de carácter religioso" (p. 107).

A diferencia de lo que comúnmente se piensa sobre la relación entre violencia, política y derecho, Benjamín invierte este orden:

[...] toda política racional encuentra su límite en la "violencia" y tiene en cambio su punto de partida legitimo en el "derecho". En su artículo, Benjamín intenta nada menos que invertir exactamente los polos de ambos conceptos en cuanto a su significado, de modo que la "violencia" parece como fuente y base, y el derecho en cambio como término de la política. (p. 107).

Antes que el derecho o la política está como fundamento la violencia, ésta acontece y es base y fundamento. Para Honneth la crítica que Benjamín lleva a cabo es una radicalización de la hecha por Kant. La experiencia es el hilo que conduce a una refundación del orden de la crítica, incluso del conocimiento. Kant había establecido el giro copernicano, pero se detuvo en la relación sujetoobjeto que nunca rebaso su condición instrumental, que Benjamín buscó superar ampliando la mirada de la experiencia, llevándola a la conciencia a su dimensión comunicativa y religiosa: “[...] Hay que tener en cuenta el plano de la experiencia que no cabe en el esquema clásico de sujetoobjeto, sino que excede su instrumentalismo en una u otra dirección" (p. 108).

La violencia es la causa eficiente del derecho y el mito, se manifiesta en cuanto afecta la moral del ser humano, en cuanto modifica su praxis de vida. Llama la atención Honneth del hecho que Benjamín excluye la violencia masculina, la intrafamiliar y su presencia en asuntos de género; ajeno también es de su atención fenómenos naturales como terremotos o erupciones de volcanes:

Hay que entender la definición de Benjamín más estrictamente en el sentido de que sólo se conciben como "violencia" los poderes coercitivos que no sólo intervienen "en una situación moral” sino que en sí mismos también están dotados de vigencia moral; en consecuencia, Benjamín se limita en su estudio al análisis de formas de violencia que tienen 
suficiente legitimidad moral para poder imponer a su vez transformaciones morales en una sociedad. (p. 109).

Este profundo sentido moral que Benjamín da a la violencia lo liga a la responsabilidad y la libertad humana, por ello, quizás, se debe entender la crítica de la violencia como su filosofía de la historia, porque recae en la decisión humana. La primera tarea, aunque insuficiente, es saber cómo se aplican esas pautas para conocer el sentido interno de los acontecimientos de una época, aunque con ello, no se alcance el juicio de valor correspondiente. Es necesario una perspectiva externa para ver las variaciones de una época histórica. Esto último es necesario para poder ver los rasgos negativos de una época, ver los acontecimientos de la historia sin juicios de valor. Un hecho es que Dios está ausente de esta época para Benjamín, se retiró y regresará, este intermedio está marcado por la corrupción y el pecado. Para Honneth nuestro pensador quiere ubicarse en un lugar para ver los acontecimientos, por ello hace una:

[...] exhortación a colocarse en un momento de la historia que se encuentre más allá del contexto de ofuscación del presente; porque sólo desde esa atalaya trascendente se puede reconocer efectivamente dónde fracasaron o fallan las pautas o distinciones practicadas actualmente. (p. 111).

Esta mirada objetiva que Honneth trata de mostrar, pero no lo dice con claridad, al igual que Bernstein, es la tradición judía. Así los términos que Benjamín usa para observar el mundo son: instauración del derecho, conservación de derecho, forma pura de creación divina que Benjamín llama violencia pura; también usa dos figuras, una divina y otra humana. Tratando de sintetizar el camino de la crítica, según Honneth para Benjamín es ir de la experiencia a la ética, de ésta a la historia, mostrar las tareas o funciones de la historia que podemos pensar como conceptos y de estos a las figuras de las que deviene el todo: el hombre y Dios:

Ahora bien, Benjamín cree poder arribar realmente al juicio de "valor" de estas distinciones sólo colocándose en la perspectiva de otra época, de una época "nueva", de la que aquí en principio sólo se nombra como cualidad más sobresaliente de derogación del 
derecho; si bien en el último párrafo de halla varias veces la expresión "divino" para ese periodo futuro, lo decisivo para la intención normativa parece ser el hecho de que con el derecho también se extinguirá el predomino de medios y fines. (p. 113).

Para Honneth, en el pensamiento de Benjamín, se ve que el derecho se reduce a simple cálculo, producto de la reificación capitalista, esto lo acerca a Lukács que se basó en la distinción de forma y contenido, mientras que Benjamín centró su crítica en la reducción al esquema medios-fines, propia del utilitarismo, así como a la oposición entre moral y derecho que defendía Sorel. Este último pensador influyó profundamente en Benjamín, que suponía que el orden social requería legitimación y que lo procuraba a través del ejercicio del derecho, ello garantiza la seguridad a la clase social privilegiada y muestra con ello la claridad de su conciencia. Esta oposición entre moral de clase o ideología, que el utilitarismo provee a los privilegiados, frente a la moral real, auténtica, que corresponde a los oprimidos, constituye la tensión de miradas de la época. Mientras que Lukács supone que el problema es la abstracción o formalización vacía del derecho, para Benjamín, basado en Sorel, el problema es la reducción a la utilidad, al fin de cada cosa o su instrumentalidad (Cfr. Honneth, 2009, p. 115).

Honneth recurre al jurista Jehring, que fue muy conocido en el momento de la redacción del ensayo, para dar sentido a las ideas de Benjamín. El jurista supone que el derecho debe garantizar las condiciones de vida de la sociedad, pero se ha convertido en una institución que garantiza el dominio de los privilegiados, oponiéndose al altruismo voluntario propio de la moral intersubjetiva que influyó en el amigo de Brecht y que podrían ser ajenas a la violencia. El egoísmo humano, propio del capitalismo, necesita orden social para evitar el conflicto, es decir, del auxilio de fuerzas autoritarias. La relación que invierte Benjamín permite ver la violencia como lo que acontece, que la razón utilitarista se ubica en su explicación en el esquema medios-fines y que es la justificación de la violencia para conservar el orden, por ello, esta tarea de justificar constituye la sustancia del derecho. El derecho es un instrumento que naturaliza la violencia, esta reducción permite a Benjamín reconocer que hay violencia sancionada y violencia no sancionada. El gran criminal es 
sancionado porque sus actos violentos abren la posibilidad de instaurar un nuevo orden jurídico, "la ley de ojo por ojo, diente por diente" tendría posibilidad de establecerse si el Estado no lo castiga. La huelga general de trabajadores es castigada por el Estado, para que los obreros no impongan condiciones ajenas a las previamente establecidas sobre el trabajo, aun cuando la huelga parcial está permitida legalmente, ello muestra la contradicción en la que cae el orden jurídico. Lo mismo sucede con la guerra entre naciones, que termina por modificar lo establecido introduciendo nuevas condiciones al contexto internacional. Lo referente a la huelga general, como lo expone Benjamín a Honneth le parece frágil e inverosímil.

Honneth piensa que los ejemplos de Benjamín, para ejemplificar la violencia que conserva derecho, tal es el caso de la pena de muerte, no obedece al esquema medios-fines que es base de su tesis. La violencia policiaca está por encima de la fundación y conservación del orden jurídico; es violencia tétrica, antinatural y humillante, cuya degeneración en la democracia parlamentaria se hace más evidente. Para Honneth, Benjamín pone lo específico de su tiempo como si fuera valido para todas las épocas, resaltando que las democracias han dado otros fines a la policía.

La ubicación futura que permite la visión objetiva a Benjamín, visión trascendente de toda moralidad que llama "pura" y que ligará a formas no violentas, de lo que están excluidos los contratos y los sistemas parlamentarios. Honneth atribuye a Benjamín aversión al sistema parlamentario, lo que lo ubica muy cercana a la postura de Schmitt, pero considera que es "[...] un comentario lanzado al margen" (p. 128). Las opciones frente a la violencia son "las 'virtudes' emocionales que permiten compenetrarse con el otro adoptando su perspectiva". (p. 128) Estos afectos son puros y se podrían sumar a la "cultura del corazón" que permitirían acuerdos sociales y a la diplomacia para las negociaciones. La huelga general proletaria, siguiendo Benjamín a Sorel, la pone como medio puro no violenta porque ejecuta la subversión:

[...] este giro asombroso en la argumentación es que parece sumarse ambivalentemente; porque "puro" casi no puede o ya no puede significar aquí "exento de violencia", sino que tiene que significar algo así "exento de finalidad", es decir, la ejecución de una acción por la acción misma. (pp. 129-130). 
No se es ajeno a la violencia sólo se está fuera de los fines, con ello Benjamín procura una visión de una época más allá del derecho:

En el desplazamiento reconocible allí queda expresado en qué dirección Benjamín buscará en la última parte de su artículo una forma de violencia que ya no forme parte del "círculo mágico" de las "situaciones de vida" tratadas hasta ahora y que por lo tanto esté libre de la relación medios fines del derecho: esa violencia, de las que las condiciones dadas la huelga general proletaria es un símbolo ejemplar, ya no puede seguir sirviendo como medio para fines morales, sino que tiene que ser ella misma expresión y forma de la ejecución de la moralidad (p. 130).

Esta ejecución de la moralidad es la violencia pura. La violencia del orden jurídico no se puede justificar porque carece de legitimación, su legitimidad de los medios está en contradicción con la justicia de los fines. Hay violencia que sólo acontece, tal como la ira, este tipo de violencia es ajena al derecho, es producto de una voluntad. Hay entonces dos tipos de violencia, la que está ligada al esquema medios-fines, propia del derecho, y la otra, la que sólo se manifiesta y que está compuesta por la violencia mítica y la violencia pura. Sin embargo, la violencia mítica, que es base y fundamento de la violencia jurídica, cumple su misma función:

Y aquí tenemos a la vista por primera vez toda la tabla de categorías sobre lo que Benjamín basó su estudio desde un principio como un esquema normativo oculto; si bien el concepto de "violencia divina" ya había aparecido por el sentido en la página anterior, recién ahora se puede ver la importancia eminente que tiene para concluir la argumentación en su conjunto. (p. 134).

Con esto podemos entender, según Honneth, porque la crítica de la violencia es su filosofía de la historia: "A esta altura no es difícil ver que Benjamín ha introducido los conceptos centrales de su tratado en un orden cronológico que está en relación inversa con su importancia objetiva o histórica" (p. 134). Podríamos decir que falta la idea del primer pecado para que de ahí emerja la 
violencia pura o divina, que procura corregir el mal introducido por la soberbia de Adán. Al deambular sólo, lleno de soberbia, el hombre juzga su propia violencia y ese juicio le permite darle un sentido mítico y jurídico, ajeno a los medios limpios y puros:

Si ahora nos imaginamos este eje genealógico como un esquema, como una columna de conceptos en cuyo extremo se encuentra la categoría de la violencia inmediata "impura", tendremos que imaginarnos además en forma paralela una segunda comuna de conceptos que sirve para registrar una genealogía completamente distinta, porque en el extremo está situada la categoría de la violencia inmediata "pura". (p. 135).

Esta violencia pura e inmediata sólo Dios puede ejecutarla dada su voluntad buena y justa. Hay para Honneth un orden de exposición que va del derecho a la violencia divina pasando por el mito, sin embargo, el proceso es inverso respecto al orden ontológico. En la época del derecho ha habido manifestaciones de la violencia divina por ello aparecen en el devenir histórico. Benjamín parece querer decir que la violencia de Dios es similar a la de los progenitores, tutores o profesores que procuran el bien a quien reprenden.

Políticamente, dice Honneth, Benjamín nos presenta una continuidad débil, intermitente de la violencia pura e inmediata como muestra que la revolución es inevitable, pero subraya, no piensa en la subversión armada sino en una revolución cultural, cuyo impacto derribaría las relaciones jurídicas del sistema en su totalidad:

Benjamín está convencido de que de ese hechizo del derecho sólo puede liberarnos en definitiva una revolución que produzca justicia inmediatamente, en una forma sagrada, mediante la ejecución de la violencia. No sorprende que un escrito con semejante contenido, cuyo concepto de derecho es terrorista, cuyo ideal de violencia es teocrático y cuya idea de revolución es escatológica, hasta hoy haya consistido esencialmente interpretaciones minimizadoras, acaparadoras o parcializadora.s (p. 138). 
Para Benjamín, moralmente sólo la violencia divina puede liberarnos de la fatalidad del derecho, afirma Honneth, pero podría pensarse en una conversión cultural, aun cuando el texto claramente sugiera la violencia como único medio.

Un punto relevante de Honneth es que trata de reconstruir el contexto en que se redactó el ensayo de Benjamín, pero no va más allá que lo inmediato al texto, no acude a la tradición judía que tiene un enorme peso en las ideas que componente el escrito. Eduardo Maura Zorita complementa la interpretación de Honneth, a quien sigue cuidadosamente en su comentario, al agregar la influencia teológica en el debate político y que tuvo un fuerte impacto en la conformación de las ideas del ensayo (Benjamín, 2010a).

Bernstein está convencido que los humanos debemos evitar la violencia, que no debe ser una opción entre las muchas que se presentan en el curso de nuestra vida, que la ayuda provendrá de nuestra capacidad para pensar, donde esté necesariamente el diálogo con el otro, que incorporemos sus ideas y sus interrogaciones como parte esencial de nuestra reflexión. Con ello está cerca de lo afirmado por Honneth, se trata de revolucionar nuestra mente para que en lugar que choque con otra la incorpore como algo fundamental de nuestra vida, para ello Bernstein cuenta con un preciado recurso: el pluralismo falibilista. Esta disposición ayudará a enfrentar dificultades que nos involucran con otros y que necesariamente son parte esencial de la solución. El reconocer que hay otras formas de pensar nos ayuda aprender de ellas, pero ello requiere que dejemos atrás lo que nos impide este acercamiento, es decir dejar a un lado las barandillas que tanto estorban y determinan nuestros prejuicios.

A manera epilogo podríamos extraer lo siguiente:

- Para Bernstein el punto nodal de una adecuada interpretación del texto de Benjamín está en el problema de la decisión, ello no se contrapone con las distintas visiones que otros pensadores tienen sobre el ensayo, más bien las refuerza y permite ver detalles singulares sobre cada una de ellas. El punto álgido está en las distintas interpretaciones de la violencia divina. 
- En el caso de Žižek se nos muestra como una interpretación muy forzada por tratar de justificar el uso de la violencia para la construcción de un mundo más justo. El problema radica en determinar en qué momento se pude acudir a la violencia y si una vez realizados los actos violentos estos fueron absolutamente necesarios y si logramos con ello evitar daños mayores. Lo que desconcierta Bernstein es que Žižek reduce el tribunal de la conciencia a llevarse a cabo en soledad e individualmente sobre la deliberación de los hechos, aquí es donde el pluralismo falibilista es necesario, que impulsa a buscar su valoración en pluralidad, sin previas concepciones y que puede ayudar a disminuir los posibles errores. El resentimiento desde luego que está presente en las acciones humanas que buscan justicia, pero con ello se liga al esquema de medios-fines la interpretación de la violencia, que era justo lo que Benjamín trata de superar como lo señala Bernstein. En conjunto estas observaciones que Bernstein hace a Žižek son válidas para las versiones de Butler y Critchley.

- En el caso de la interpretación de Derrida, quien procura una tarea cercana a la Bernstein, cuestionar a los textos, llevarlos a su sentido aporético, pero mantiene una mayor rigidez en su juicio, menos dialógica, faltó quizás al pensador deconstruccionista tener la actitud del pluralismo falibilista como actitud de fondo. Aun cuando Bernstein no rechaza el ejercicio imaginario de buscar las opiniones de Benjamín sobre el holocausto como lo hace Derrida, sin embargo, le parece exagerado el vínculo que el pensador francés trata de establecer entre la violencia divina y la "solución final". La diferencia de ambos pensadores radica en la tradición, Bernstein parte de los acontecimientos más próximos al origen del ensayo, al igual que Honneth, mientras que Derrida quiere hacer visible la concepción judía que está de trasfondo en el pensamiento de Benjamín y, sobre todo, denuncia que hay formas de pensar y pensamientos que por su naturaleza son coherentes con hechos y acontecimientos violentos. Esto último coincide con la idea de Bernstein que hay diferentes mentalidades que pueden colisionar, ello en relación a catalogar al otro como encarnación del mal, creando una retórica de justificación para poder atacarlo y exterminarlo, de ello nos libra el 
pluralismo falibilista (Cfr. Bernstein, 2006). En ambos casos, la deconstrucción y el pluralismo falibilista están en tensión con mentalidades que ponen al extraño, al otro, como encarnación del mal, blindando de las perniciosas ideas que provienen de la tradición.

- Gillian Rose, Dussel, Salinas Paz, Ortega Esquivel, entre muchos otros, usando la expresión de Honneth para referir la interpretación de Marcuse, minimizan el pensamiento de Benjamín; hacen decir al berlinés que "revolución mesiánica" es la lucha de los oprimidos contra los poderosos, cuando lo que se busca es la lucha contra el pecado en todas sus manifestaciones. Hay dos puntos a mi juicio valiosos en el texto de Benjamín, primero pensar la violencia de manera independiente de todo contexto de justificación, es decir, como hecho, como lo que acontece; para de ahí poder enfocarla moralmente. ¿Cómo hecho es moralmente justificable la violencia? Obviamente la respuesta es no. La violencia no debe tener lugar en el mundo en ninguna de sus manifestaciones ¿Cómo evitarla? Para Benjamín hay ciertos recursos que parten de virtudes individuales a través de acuerdos ajenos a los contratos jurídicos, tras esta idea está el nombre, que es vital en la tradición judía, conserva algo de lo que tuvo en tiempos previolentos y con esa débil luz iluminar, darle fuerza a la palabra que compromete a las partes, para sellar el compromiso entre ellas; ello necesita, aun cuando parezca contradictorio, según Benjamín la idea de no castigar la mentira y el engaño. Aun cuando no lo dice, pero parece que habría una función similar a lo que Dios hace con el mandamiento "no matarás" y tendríamos que pensar que observa las actividades humanas como simple espectador sabiendo que ha dicho "no mentirás". Benjamín marginalmente hace extensiva esta posibilidad a otras formas de acuerdo, a aquellas que son acuerdos de grupos o diplomáticas, ello nos haría pensar en propuestas como la teoría coalescente de la argumentación de Michael A. Gilbert (Cfr: Gilbert, 2017) que propone mecanismos para que la diferencia de ideas seda y se puedan alcanzar acuerdos; ello dista mucho de la idea de Benjamín, quien rechaza la argumentación como el medio adecuado para este fin y considera que la vía es la revelación divina a través del 
nombre, misticismo que desborda la capacidad de humana. Estos puntos son valorado por Bernstein y en buena medida su propuesta filosófica discurre por este sendero.

- La no violencia en el escrito de Benjamín no tiene la fuerza que tiene la violencia, se reduce a la "cultura del corazón", al acuerdo fuera del marco legal entre particulares que confían en la palabra empeñada, estaría soportada en medios limpios de conformidad no violenta y para conservar esa pureza debe cuidar en no caer en la relación medios-fines propia del derecho. Esta forma débil, pero esencial del texto de Benjamín, coincide plenamente con la intensión del filosofar de Bernstein.

- Del texto de Benjamín se sigue que la violencia es inevitable, es inherente a la vida de los seres humanos, sin embargo, no está en su naturaleza. La violencia acontece porque el hombre juzga, descalifica las acciones, pensamientos y sentimientos de los otros. El acto de juzgar proviene de la ignorancia del ser humano; esto se debe a que perdió el nombre que nombra las cosas y los hechos, esta carencia lo obliga a emitir opiniones sin soporte, sin referir lo que realmente acontece y, por ello, a actuar en consecuencia, a realizar acciones torpes y extraviadas, de ahí que tenga que emplear la fuerza y cometer actos de violencia para ajustar el mundo a sus ideas y pensamientos. Estos hechos adulterados y equívocos necesitan ser justificados para tener un lugar armonioso y racional, de ahí la importancia de juzgar. La única forma de superar esta condición será en el juicio final, cuando Dios reestablezca lo perdido por el pecado original, devolviendo al nombre su esencialidad. Bernstein no refiere nada de esto, pero su propuesta del pluralismo falibilismo ayudará a que la ignorancia, pero sobre todo aquello que impide superarla, disminuya e independientemente de que exista un juicio final y seguramente ello contribuirá a disminuir la violencia. Pero lo más importante, es que proponen una vía para juzgar a quienes causan daño con actos violentos, de tal forma que no caiga en arbitrariedades.

- La violencia divina, se lee de formas distintas: revolución de los oprimidos, no violencia, resentimiento de las víctimas, anticipación del juicio de final, impotencia de Dios, revolución cultural, etc., lo que motivo la reflexión de Benjamín fue superar el utilitarismo, según 
Honneth, al pensamiento estancado en la representación y con ello en la Aufklärung, según Derrida, desenmascarar el engaño de la justicia injusta, según Salinas Paz, etc., pero el problema de la decisión es común y punto nodal como lo afirma Bernstein, independientemente nos gustaría saber ¿Por qué un ser humano decide por la opción violenta? Quizás debemos preguntar por el ethos de quienes interpretan, como Bernstein hace con Derrida, quien pregunta por el nombre y la firma de Benjamín. Hay un ethos involucrado en las interpretaciones que da un aire ajeno y parcial a cada interpretación del ensayo, cada interprete tiene que cuidar su prestigio, pero también la fuerza totémica del nombre Walter Benjamín.

- Siguiendo a Dewey, Bernstein es partidario de la democracia como forma de vida, un sistema de gobierno que fomente y nutra la participación de sus ciudadanos, que sea inherente a su vida cotidiana, pero lo dicho por Derrida, que, también apuesta por la democracia parlamentaria y el derecho basado en la Aufklärung, fue que Benjamín pensó negativamente sobre todo tipo de gobierno y en particular de ese. Honneth ha subrayado que la intensión de Benjamín es poder observar los acontecimientos desde una época no violenta, ajena a la racionalidad instrumental del derecho, donde la participación de los integrantes de ese mundo pueda, por el valor de su palabra, alcanzar acuerdos ajenos a formas jurídicas, tales como contratos y deliberación parlamentaria, que caracteriza a las democracias de hoy. Cómo conciliar la postura de Benjamín contra la democracia parlamentaria y el derecho, con la postura de sus intérpretes, donde todos ellos de una forma u otra procuran un sistema de gobierno que podríamos llamar "democracia"; en un segundo momento, exceptuando a Derrida y Scholem, todos dialogan con Benjamín sin considerar la fuerza que hay en su pensamiento de la tradición judía, lo consideran parte de la tradición occidental, cuando él mantiene un rechazo tajante sobre ella.

La vida, en tanto vida natural o biológica, no es sagrada, por ello no tiene valor, es un recurso que puede exterminarse según Benjamín; solo la vida justa, y justa a los ojos de Dios, es digna de ser cuidada. Lo grave de esta idea es que se funda y proviene de una tradición, el valor está 
predeterminado en ese marco cultural-religioso, en el caso de Benjamín por el judaísmo. En un sentido aporético, si seguimos el pensamiento de nuestro filósofo de mantenernos en lo concreto, en lo singular y en los hechos; de donde se sigue dejar fuera toda tradición, sólo queda la vida desnuda, la estrictamente biológica, fuera de ella nada, ni alma, ni espíritu, ni sagrada, sólo vida, que es lo único que puede sufrir violencia. Pero en sentido diferente a lo dicho, la idea de concreción para Benjamín viene a raíz del nombre que es la esencia espiritual que Dios uso para crear la cosa, la cosa es el nombre mismo; en el caso nuestro es la vida que acontece como una singularidad, aun cuando no tenga nombre, porque no exista quien lo pronuncie o dé el soplo, el aliento.

\section{Referencias}

Benjamín, W. (2001) Para una crítica de la violencia; Madrid; editorial Taurus; Trad.: Roberto Blatt. Benjamín, W. (2007) Conceptos de filosofía de la historia; Buenos Aires: ed. Terramar; Trad.: H. A. Murena y D. J. Vogelmann.

Benjamín, W. (2010a) Crítica de la violencia; Ciudad de México; Gandhi ediciones; Trad.: Héctor A. Murena (revisada por Eduardo Maura Zorita).

Benjamín, W. (2010b) Obras, Libro II/vol. I; Madrid; Abada editores; Trad.: Jorge Navarro Pérez.

Benjamín; W. (1986) Sobre el programa de la filosofía futura y otros ensayos; México D. F.; Editorial Artemisa (Planeta de Agostini S. A.); Trad.: Roberto J. Vernengo.

Bernstein, R. J. (2006) El abuso del mal. La corrupción de la política y la religión desde el 11/9; Buenos Aires; Katz editores; Trad.: Alejandra Vassallo y Verónica Inés Weinstabl.

Bernstein, R. J. (2015) Violencia. Pensar sin barandillas; Barcelona; Gedisa editorial; Trad.: Santiago Rey Salamanca.

Bojanić, P. (2010) La violencia divina en Benjamín y el caso Korah. La rebelión contra Moisés como primera escena del mesianismo; Revista Acta Poética \#31-1 (enero-junio); trad. Miriam Jarabe. 
Corona, J. (2018) Constelaciones y campos de fuerza en la Teoría crítica actual; Guanajuato; Ediciones Eon.

Derrida, J. (2016) Fuerza de ley. El "fundamento místico de la autoridad"; Madrid; Editorial Técnos; trad.: Adolfo Barbera y Patricio Peñalver Gómez.

Forster, R. (2014) La travesía del abismo. Mal y modernidad en Walter Benjamín; Buenos Aires; Fondo de Cultura Económica.

Honneth, A. (2009) Patologías de la razón. Historia y actualidad de la teoría crítica; Buenos Aires; Katz Ediciones; Trad. Griselda Mársico.

Karmy, R. (2005) Violencia mítica y vida desnuda en el pensamiento de W. Benjamín: Revista A Parte Rei. Revista de filosofía \#39.

Lizarazo, D. y Sánchez, J. A. (2012) Benjamín y las encrucijadas de la violencia; México; Editorial UAM Xochimilco.

Muñiz-Huberman, A. (1993) Las raíces y las ramas. Fuentes y derivaciones de la Cábala hispanohebrea; México D. F.; Fondo de cultura económica.

Scholem, G. (2003) Walter Benjamín y su ángel; México; Fondo de cultura económica; Trad. Ricardo Ibarlucia y Laura Carugati.

Scholem, G. (2014) Walter Benjamín. Historia de una amistad; Trad.: J. F. Yvars y Vicente Jorque.

Sorel, G. (1978) Reflexiones sobre la violencia; Buenos Aires; Ediciones la pléyade; Trad.: Luis Alberto Ruiz.

Žižek, S. (2009) Sobre la violencia. Seis reflexiones marginales; Buenos Aires; editorial Paidós; Trad.: Antonio José Antón Fernández.

Gilbert, M. A. (2017) Argumentando se entiende la gente; Guadalajara; Editorial Universitaria; Trad. Fernando Leal Carretero.

Salinas, F. (2018) 200 años con Marx; Guadalajara, ediciones CUCSH-UdeG. 